\title{
NLRP3 Inflammasome in Neurological Diseases, from Functions to Therapies
}

OPEN ACCESS

Edited by:

Hansen Wang,

University of Toronto, Canada

Reviewed by:

Gloria Lopez-Castejon,

University of Manchester, UK

Thad A. Rosenberger,

University of North Dakota, USA

Ramani Soundararajan,

University of South Florida, USA

Sharon DeMorrow,

Texas A\&M Health Science Center,

USA

Teneema Kuriakose,

St. Jude Children's Research

Hospital, USA

*Correspondence:

Yan Wu

wuyan_120@163.com

You Shang

you_shang@yahoo.com

tThese authors have contributed equally to this work.

Received: 17 December 2016 Accepted: 22 February 2017

Published: 09 March 2017

Citation:

Song L, Pei L, Yao S, Wu Y and

Shang $Y$

(2017) NLRP3 Inflammasome in

Neurological Diseases, from

Functions to Therapies.

Front. Cell. Neurosci. 11:63.

doi: 10.3389/fncel.2017.00063

\author{
Limin Song ${ }^{1 \dagger}$, Lei $\mathrm{Pei}^{2 \dagger}$, Shanglong Yao ${ }^{1}$, Yan $\mathrm{Wu}^{3 *}$ and You Shang ${ }^{4 *}$
}

${ }^{1}$ Department of Anesthesiology, Institute of Anesthesiology and Critical Care Medicine, Union Hospital, Tongji Medical College, Huazhong University of Science and Technology, Wuhan, China, ${ }^{2}$ Department of Neurobiology, School of Basic Medicine, Tongji Medical College, Huazhong University of Science and Technology, Wuhan, China, ${ }^{3}$ Department of Neurology, Union Hospital, Tongii Medical College, Huazhong University of Science and Technology, Wuhan, China, ${ }^{4}$ Department of Critical Care Medicine, Institute of Anesthesiology and Critical Care Medicine, Union Hospital, Tongji Medical College, Huazhong University of Science and Technology, Wuhan, China

Neuroinflammation has been identified as a causative factor of multiple neurological diseases. The nucleotide-binding oligomerization domain-, leucine-rich repeat- and pyrin domain-containing 3 (NLRP3) inflammasome, a subcellular multiprotein complex that is abundantly expressed in the central nervous system (CNS), can sense and be activated by a wide range of exogenous and endogenous stimuli such as microbes, aggregated and misfolded proteins, and adenosine triphosphate, which results in activation of caspase-1. Activated caspase-1 subsequently leads to the processing of interleukin-1 $\beta$ (IL-1 $\beta$ ) and interleukin-18 (IL-18) pro-inflammatory cytokines and mediates rapid cell death. $\mathrm{IL}-1 \beta$ and $\mathrm{IL}-18$ drive inflammatory responses through diverse downstream signaling pathways, leading to neuronal damage. Thus, the NLRP3 inflammasome is considered a key contributor to the development of neuroinflammation. In this review article, we briefly discuss the structure and activation the NLRP3 inflammasome and address the involvement of the NLRP3 inflammasome in several neurological disorders, such as brain infection, acute brain injury and neurodegenerative diseases. In addition, we review a series of promising therapeutic approaches that target the NLRP3 inflammasome signaling including anti-IL-1 therapy, small molecule NLRP3 inhibitors and other compounds, however, these approaches are still experimental in neurological diseases. At present, it is plausible to generate cell-specific conditional NLRP3 knockout $(\mathrm{KO})$ mice via the Cre system to investigate the role of the NLRP3 inflammasome, which may be instrumental in the development of novel pharmacologic investigations for neuroinflammation-associated diseases.

Keywords: neuroinflammation, NLRP3, inflammasome, microglia, astrocytes, IL-1 $1 \beta$, IL-18

\section{INTRODUCTION}

Neuroinflammation is a fundamental innate immune response in the central nervous system (CNS) by which the brain and spinal cord react to diverse pathogens and host-derived signals of cellular damage. Inflammatory responses are necessary steps for eliminating invading agents, clearing damaged cells and promoting tissue repair (Miwa et al., 1997; Tahara et al., 2006; Ito et al., 2007; 
Ribes et al., 2009; Szretter et al., 2009); however, uncontrolled neuroinflammation may lead to further tissue injury and neural dysfunction (Lazovic et al., 2005; Choi et al., 2009; Abo-Ouf et al., 2013). Therefore, it has become evident that neuroinflammation represents a significant cause of neurological deficits.

Researchers have recently focused their attention on a group of subcellular multiprotein complexes referred to as inflammasomes (Martinon et al., 2002), whose formation and activation may be induced by a wide range of substances (Kanneganti et al., 2006b; Mariathasan et al., 2006; Martinon et al., 2006; Sutterwala et al., 2007; Newman et al., 2010; Rathinam et al., 2010). In particular, the nucleotide-binding oligomerization domain-, leucine-rich repeat- and pyrin domain-containing 3 (NLRP3) inflammasome has gained considerable attention (Agostini et al., 2004). It is abundantly expressed in the CNS and may serve to detect noxious agents or irregularities in the cellular microenvironment (Halle et al., 2008; Yin et al., 2009; Jha et al., 2010; Geldhoff et al., 2013b; Yang et al., 2014). Activated NLRP3 inflammasome leads to the activation of caspase-1, which mediates the production of interleukin-1 $\beta$ (IL-1 $\beta$ ) and interleukin-18 (IL-18) pro-inflammatory cytokines and the initiation of a rapid form of cell death termed pyroptosis (Martinon et al., 2002; Kanneganti et al., 2006a; Fink et al., 2008). IL-1 $\beta$ and IL-18, in turn, initiate multiple signaling pathways and drive inflammatory responses, which results in neuronal injury or death (Yatsiv et al., 2002; Bossù et al., 2010; Meissner et al., 2010; Wilms et al., 2010). Therefore, the NLRP3 inflammasome plays a crucial role in the development of inflammatory responses in the CNS. Moreover, emerging studies have revealed the involvement of NLRP3 signaling in several neurological disorders (Gris et al., 2010; Hoegen et al., 2011; Fann et al., 2013b; Heneka et al., 2013; Johann et al., 2015).

Herein, we describe the general principles involved in the structure and activation mechanisms of the NLRP3 inflammasome in the CNS, as well as the complex neuroinflammatory signaling pathways and consequences associated with NLRP3 inflammasome activation under the circumstances of brain infection, acute injury and neurodegenerative disorders. Finally, we conclude that NLRP3 inflammasome signaling may represent a promising therapeutic target for the treatment of neuroinflammationassociated neurological diseases.

\section{MICROGLIA AND ASTROCYTES IN NEUROINFLAMMATION}

Emerging evidence supports the notion that various pathological changes within the CNS elicit a prominent inflammatory reaction referred to as neuroinflammation. In the CNS parenchyma, microglia and astrocytes are the primary effectors of neuroinflammation (Karve et al., 2016; Shrivastava et al., 2017). Plasma membrane pattern recognition receptors (PRRs) expressed on glial cells play an important role in the activation of nuclear factor- $\kappa \mathrm{B}$ $(\mathrm{NF}-\kappa \mathrm{B})$ and mitogen-activated protein kinase inflammatory pathways (Tang et al., 2013; Heneka et al., 2014). In addition, microglial-astrocyte communication is highly important in CNS innate immunity.

Microglia, the resident macrophage-like cells of the CNS, are derived from yolk-sac myeloid progenitors during the early stage of embryonic development (Kierdorf et al., 2013). They continually monitor and survey their assigned brain regions and participate in CNS development, neuroprotection, and the maintenance of hemostasis (Paolicelli et al., 2012; Nayak et al., 2014). Microglia express numerous PRRs that are responsible for the early recognition of pathogen-associated molecular patterns (PAMPs) and damage-associated molecular patterns (DAMPs), such as Toll-like receptors (TLRs), NOD-like receptors (NLRs), retinoic acid-inducible gene-I-like receptors and triggering receptor expression on myeloid cells 2 (TREM2; Shah et al., 2008; Kumar et al., 2011; Hu et al., 2012; Fu et al., 2014). Microglial cells are considered the earliest responders to pathological insults on the CNS (Becher et al., 2000; Saijo et al., 2013). Under non-pathological conditions, microglial cells have a highly ramified appearance. Upon detecting environmental challenges, such as brain injury, infection, or protein aggregates, microglia become rapidly "activated" and transform to an ameboid appearance with increased expression of major histocompatibility complex molecules and other markers (Rock et al., 2004; Kettenmann et al., 2011). Proliferation and migration of microglial cells also occur (Byrnes and Faden, 2007). Moderate microglial responses exert protective effects on the CNS in some circumstances (Lalancette-Hébert et al., 2007). Nevertheless, over-activated microglia can lead to neuroinflammation, oxidative stress and neuronal dysfunction due to the excess production of a wide range of cytotoxic factors, such as tumor necrosis factor- $\alpha$ (TNF- $\alpha)$, IL-1 $\beta$, IL-18, IL-6, reactive oxygen species (ROS) and nitric oxide (NO; Moss and Bates, 2001; Heneka and O'Banion, 2007; Nayak et al., 2014). Moreover, the interaction between microglia and other immune cells results in secondary inflammatory responses. Recent findings have involved microglia activation in the initiation and maintenance of inflammatory responses in the context of infectious brain diseases, acute CNS injury and several neurodegenerative diseases (Aoki et al., 2009; Fellner et al., 2013; Elmore et al., 2014; Liu et al., 2015; Kumar et al., 2016; Li D. et al., 2016; Xian et al., 2016).

Similar to peripheral macrophages, several broad classifications of microglia M1, M2a, M2b and M2c have been identified in the literature (Geissmann et al., 2010; Franco and Fernández-Suárez, 2015). "Classically activated" M1 microglia, which exhibit an ameboid appearance, strong phagocytic capability and high mobility, are characterized by the generation and secretion of large amounts of pro-inflammatory mediators and high levels of oxidative production (Loane and Byrnes, 2010; Zhang et al., 2016). Generally, "alternatively activated" M2 microglia exhibit a hyper-ramification appearance (Cherry et al., 2014) and produce plenty of anti-inflammatory cytokines, neurotrophic factors, and extracellular matrix molecules (David and Kroner, 2011; Michell-Robinson et al., 2015). Therefore, M2 microglia are primarily associated with the resolution of inflammation and tissue repair. Three subclasses of M2 microglia exhibit slight differences in cellular markers and 
functions. M2b microglia are characterized by large amounts of pro-inflammatory cytokine generation and by high IL-10 and low IL-12 expression (Ferrante et al., 2013; Orihuela et al., 2016), which allows them to be able to shift to a mixture of M1 and $\mathrm{M} 2 \mathrm{a} / \mathrm{b}$.

Substantial numbers of astrocytes are present in the CNS parenchyma, and they perform a diverse array of functions including glutamate uptake, fuel provision, synaptogenesis, structural support and immune defense (Brown and Ransom, 2007; Perea et al., 2009, 2014; Barreto et al., 2011). Astrocytes display a great degree of heterogeneity in their morphology, lineage, anatomical locations and gene expression profile (Zhang and Barres, 2010; Sosunov et al., 2014). Astrocytes are equipped with various innate immune receptors, and they directly respond to different types of CNS insults with hypertrophy and hyperplasia, a process referred to as astrogliosis. Astrocytes, however, are involved in the formation of compact astrocytic scars by forming and orienting long processes toward the core of severely damaged sites (Cregg et al., 2014). Under normal circumstances, reactive astrogliosis and scar formation are essential for confining CNS inflammation to the lesion epicenter, protecting neural networks and promoting repair of the blood-brain barrier (BBB; Pekny and Nilsson, 2005; Sofroniew, 2005, 2009). However, under pathological conditions, astrogliosis can interfere with neurite growth and regeneration (Silver and Miller, 2004; Anderson et al., 2014; Cregg et al., 2014). Moreover, reactive astrocytes produce numerous pro-inflammatory mediators, such as cytokines, chemokines and NO, which makes them essential for exacerbating inflammatory responses. Notably, by regulating specific signaling events, astrogliosis can exert either potent pro-inflammatory effects or essential anti-inflammatory effects.

\section{NLRP3 INFLAMMASOME}

The NLRP3 inflammasome was first characterized in MuckleWells Autoinflammatory Disorder (Martinon et al., 2002; Agostini et al., 2004). NLRP3 inflammasome can sense various stimuli and form a molecular platform for caspase- 1 activation, which leads to the processing and release of IL-1 $\beta$ and IL-18 and eventually potentiates inflammatory responses that are involved in multiple infectious, inflammatory and immune diseases (Sutterwala et al., 2006; Willingham et al., 2007; Halle et al., 2008; Masters et al., 2010; Walsh et al., 2014). Thus, the NLRP3 inflammasome is of crucial importance in the development of both acute and chronic inflammatory responses.

The NLRP3 inflammasome mainly consists of a cytosolic sensor molecule NLRP3, an adaptor protein apoptosis-associated speck-like protein containing a caspase activating recruitment domain (ASC), and a cysteine protease pro-caspase-1 as the effector molecule (Agostini et al., 2004; see Figure 1).

NLRP3 contains a C-terminal leucine-rich repeat (LRR) domain, a conserved central nucleotide binding and oligomerization domain (NOD or NACHT), and an N-terminal pyrin-only domain (PYD; Anderson et al., 2004). The LRR domain recognizes PAMPs and other ligands, maintains the NLRP inactive state, and mediates protein-protein interactions (Meng et al., 2003; O’Connor et al., 2003; Hoffman et al., 2010). The NACHT domain, with ATPase activity, is essential for protein self-oligomerization during the inflammasome assembly

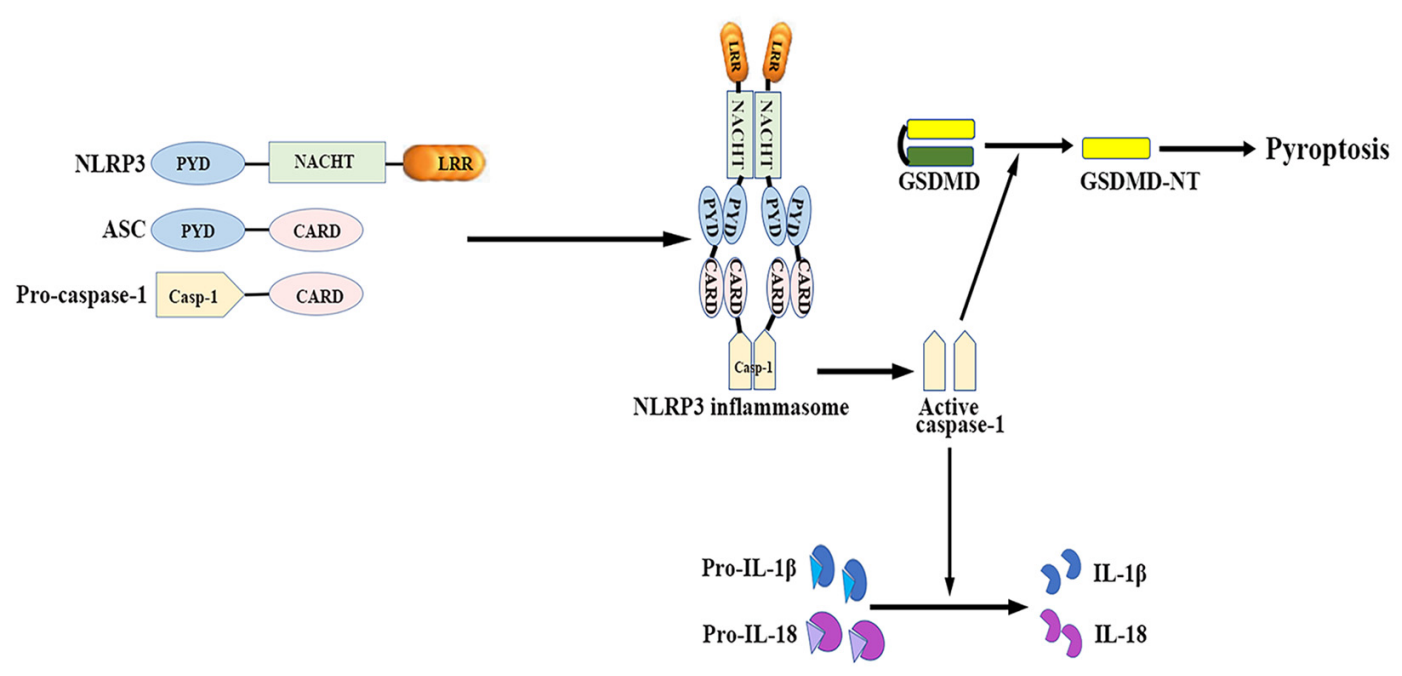

FIGURE 1 | NLRP3 inflammasome: structure and function. The NLRP3 inflammasome mainly consists of the cytosolic sensor molecule NLRP3, the adaptor protein ASC, and the effector molecule pro-caspase-1. The assembly and activation of NLRP3 inflammasome results in caspase-1 activation. Activated caspase-1 subsequently leads to the maturation of IL-1 $\beta$ and IL-18, as well as mediates a form of inherent inflammatory cell death termed as pyroptosis. ASC, apoptosis-related speck-like protein containing a caspase recruitment domain; CARD, caspase activation and recruitment domain; GSDMD, gasdermin D; GSDMD-NT, gasdermin-N domain of GSDMD; IL, interleukin; LRR, leucine-rich repeat; NACHT (NOD), nucleotide binding and oligomerization domain; NLRP3, nucleotide-binding oligomerization domain-, leucine-rich repeat- and pyrin domain-containing 3; PYD, pyrin-only domain. 
process (Duncan et al., 2007). The PYD enables protein-protein homotypic interactions between NLRP and the bipartite adapter ASC (Liepinsh et al., 2003).

ASC consists of an N-terminal PYD and a C-terminal caspase activation and recruitment domain (CARD; Masumoto et al., 1999). ASC binds to the upstream NLRP3 through a homotypic PYD-PYD domain interaction, which results in ASC dimer assembly into a large speck-like structure (Dowds et al., 2004). ASC interacts with pro-casapase- 1 via the CARD domain (Srinivasula et al., 2002).

Caspase- 1 is present as a catalytically inactive precursor procaspase-1 in unstimulated cells. Pro-caspase-1 recruitment, which is mediated by ASC, contributes to caspase-1 oligomerization and auto-proteolytic conversion of the pro-enzyme into its active form (Agostini et al., 2004). The active caspase- 1 fragments elicit the maturation and secretion of pro-inflammatory cytokines IL-1 $\beta$ and IL-18, which belong to the IL-1 $\beta$ family and mediate subsequent immune responses (Keller et al., 2008).

Caspase-1 activation also induces a form of inherent inflammatory cell death, referred to as pyroptosis, which is characterized by rapid plasma-membrane rupture, DNA fragmentation, and the release of pro-inflammatory cytosolic contents into the extracellular space (Bergsbaken et al., 2009). Pyroptosis is both morphologically and mechanistically different from apoptosis and other forms of cell death. Recent studies have identified that activated caspase-1 cleaves gasdermin D (GSDMD) to generate the gasdermin-N domain of GSDMD (GSDMD-NT), which can directly bind phosphoinositides and cardiolipin (Shi J. et al., 2015; Ding et al., 2016; Liu et al., 2016). GSDMD-NT then associates with the plasma membrane and oligomerizes to form non-selective pores, which triggers cell swelling and lysis (Chen et al., 2016; Liu et al., 2016). Both neurons and glial cells may trigger this process of cell death in response to a wide range of pathological stimuli (Adamczak et al., 2014; Tan et al., 2014; Kim et al., 2015).

\section{ACTIVATION AND REGULATION OF THE NLRP3 INFLAMMASOME}

The NLRP3 inflammasome is the most extensively investigated inflammasome, and it is present in microglia and astrocytes in the CNS (Cho et al., 2014; Lu et al., 2014; Zendedel et al., 2016). It remains debated whether neurons express NLRP3 (Fann et al., 2013a; Yang et al., 2014; Kaushal et al., 2015). In vitro studies suggest that the basal level of NLRP3 in resting cells is not sufficient to activate the inflammasome. It is widely accepted that successful NLRP3 inflammasome activation requires a two-checkpoint signal process. A priming signal is provided by the NF- $\kappa \mathrm{B}$-activating stimuli to transcriptionally enhance the expression of NLRP3 and pro-IL-1 $\beta$ (Bauernfeind et al., 2009). Many TLR and NLR ligands, as well as endogenous cytokines such as IL- $1 \alpha$, have been demonstrated to prime cells. The subsequent activating signal is provided by various NLRP3activating agents to promote the formation of the inflammasome complex. A wide range of exogenous and endogenous stimuli including PAMPs, aggregated and misfolded proteins, ATP and crystalline substances induce NLRP3 activation (Mariathasan et al., 2006; Martinon et al., 2006; Halle et al., 2008; Demento et al., 2009; Duncan et al., 2009; Shi F. et al., 2012).

Given the broad array of NLRP3 activators, NLRP3 appears to sense the disturbance of cellular homeostasis rather than directly react to these stimuli. To elucidate this, researchers have proposed several theories as follows: (1) low intracellular $\mathrm{K}^{+}$concentration may play a major role in common signal transduction for NLRP3 activation (Pétrilli et al., 2007; MarinaGarcía et al., 2008; Karmakar et al., 2016); (2) endo-lysosomal destabilization induces the release of cathepsins into the cytosol, which may directly activate NLRP3 (Hornung et al., 2008; Sharp et al., 2009; Bruchard et al., 2013); (3) ROS, mitochondrial DNA and phospholipid cardiolipin released from damaged mitochondria activate NLRP3 (Zhou et al., 2010, 2011; Subramanian et al., 2013); (4) $\mathrm{Ca}^{2+}$ flux and the $\mathrm{Ca}^{2+}$-dependent signaling trigger the assembly of NLRP3 inflammasome (Feske et al., 2012; Lee et al., 2012; Murakami et al., 2012).

The activity of NLRP3 is finely regulated through distinct mechanisms. Recent studies have revealed that BRCC-3, doublestranded RNA-dependent protein kinase, death-associated protein kinase 1 and Bruton's tyrosine kinase function as endogenous positive regulators of NLRP3 inflammasome activity (Chuang et al., 2011; Juliana et al., 2012; Lu et al., 2012; Py et al., 2013; Ito et al., 2015). A member of the NIMA-related kinase (NEK) family, NEK7 has been shown to directly bind to the LRR domain of NLRP3 and act downstream of $\mathrm{K}^{+}$efflux and ROS generation to promote the assembly of NLRP3 inflammasome (He et al., 2016; Schmid-Burgk et al., 2016; Shi et al., 2016). Nevertheless, autophagy, microRNAs, CARD-only proteins, pyrin-only proteins and $\mathrm{NO}$ act as endogenous negative regulators of NLRP3 (Saitoh et al., 2008; Hernandez-Cuellar et al., 2012; Shi C. S. et al., 2012; Mishra et al., 2013; de Almeida et al., 2015; Qin et al., 2015; Yang et al., 2015).

\section{EFFECTS OF INFLAMMASOME ACTIVATION ON NEUROINFLAMMATION}

The NLRP3/caspase-1/IL-1 axis has emerged as a critical signaling pathway of the innate immune system in the CNS (Rosenzweig et al., 2011; see Figure 2). The abundance of caspase-1 has been identified in the context of neuroinflammation-related disorders (Sifringer et al., 2007; de Rivero Vaccari et al., 2016). IL-1 $\beta$ and IL-18 are cytokines that are matured by the NLRP3 inflammasome. The involvement of IL-1 $\beta$ and IL-18 in neuroinflammation has long been speculated (Arend et al., 2008; Dinarello et al., 2012). High levels of IL-1 $\beta$ and IL-18 have been demonstrated in the cerebrospinal fluid (CSF), brain tissue and plasma of patients with CNS infection, brain injury and neurodegenerative diseases such as Alzheimer's disease (AD) and multiple sclerosis (MS; Licastro et al., 2000; de Jong et al., 2002; Huang et al., 2004). Both IL-1 $\beta$ and IL-18 bind to their respective receptors on microglial cells, astrocytes, neurons and endothelial cells, thereby triggering a complex spectrum of signaling events, which results in secondary expression of multiple inflammation-associated genes. Notably, cytokine-mediated processes were shown to be 


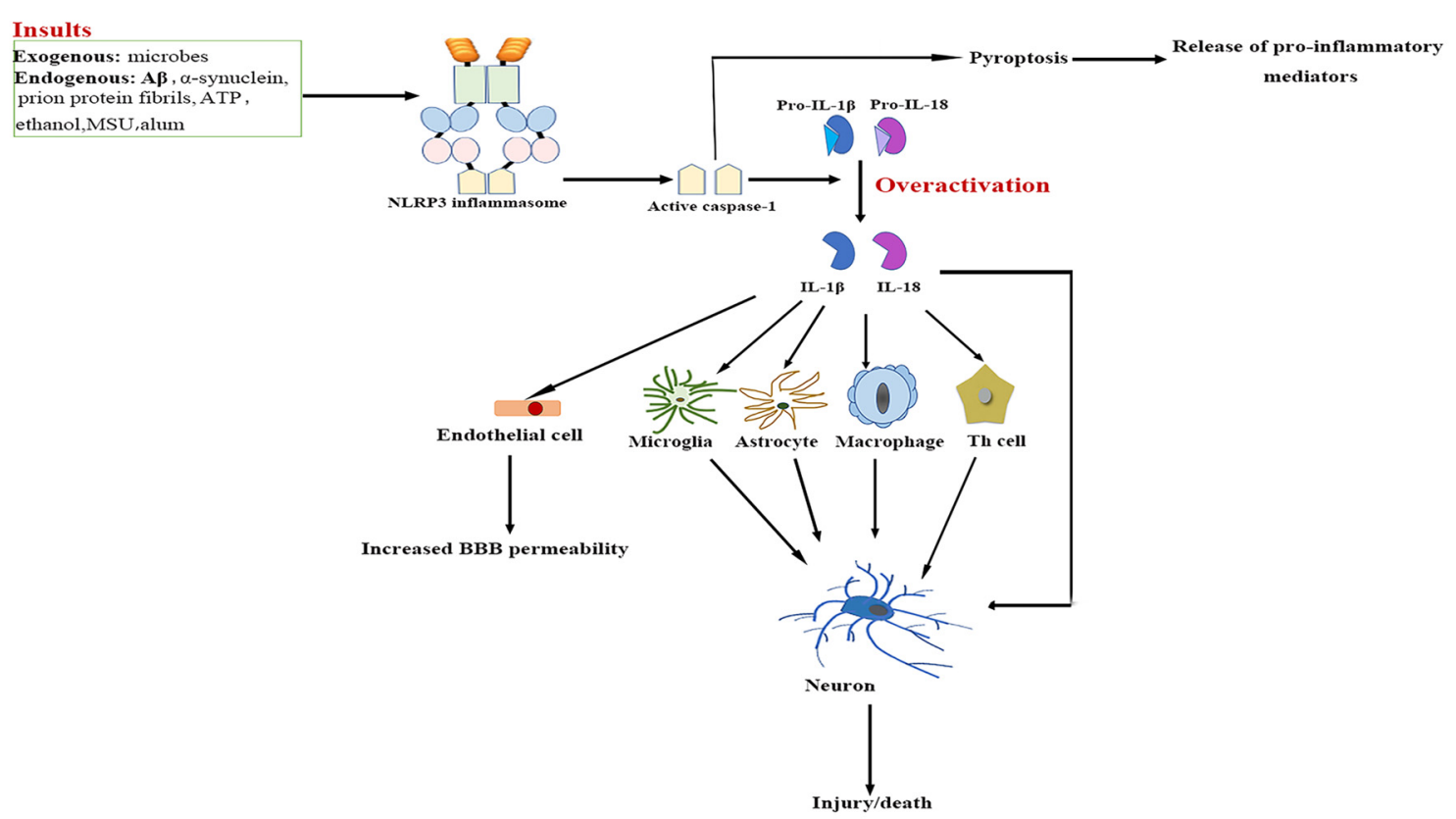

FIGURE 2 | NLRP3 inflammasome activation-mediated neuroinflammation. Upon activation by a wide range of exogenous and endogenous stimuli, the NLRP3 inflammasome located in microglia and astrocytes trigger the maturation of IL-1 $\beta$ and IL-18 and induce pyroptotic cell death. The high levels IL-1 $\beta$ and IL-18 bind to their receptors on glial cells, neurons, macrophages and endothelial cells, as well as cooperate with other cytokines to initiate Th-cell signaling, thereby triggering a complex spectrum of signaling events, which results in exacerbation of inflammatory cascade responses within the central nervous system (CNS). A $\beta$, $\beta$-amyloid; ATP, adenosine triphosphate; BBB, blood-brain barrier; IL, interleukin; MSU, monosodium urate; NF-кB, nuclear factor-kB; NLRP3, nucleotide-binding oligomerization domain-, leucine-rich repeat- and pyrin domain-containing 3; Th, T helper.

involved in cognitive decline and have been verified to lead to long-term neuropsychiatric disorders (McAfoose and Baune, 2009).

IL-1 $\beta$ signaling plays a major role in the initiation and continuation of the inflammatory reactions in the CNS in response to various adverse stimuli (Cannon, 2000). IL-1 $\beta$ contributes to modulating the integrity of the $\mathrm{BBB}$, which results in the infiltration of peripheral immune cells into the CNS (Alvarez et al., 2011). IL-1 $\beta$ also stimulates the activation of microglia and astrocytes, which in turn activates CNS-infiltrated $\mathrm{T}$ cells and induces the generation of additional pro-inflammatory factors such as IL- 6 and TNF- $\alpha$, as well as neurotoxic mediators (Ferrari et al., 2004). Moreover, IL-1 $\beta$ indirectly recruits leukocytes by augmenting the expression of chemokines (Gosselin and Rivest, 2007). Several experimental studies have even demonstrated that over-expression of IL-1 $\beta$ mediates neuronal injury by regulating glutamate excitotoxicity (Hu et al., 2000; Fogal et al., 2007).

IL-18 mainly stimulates T-helper (Th) cell-mediated immune responses by inducing the production of adhesion molecules, pro-inflammatory cytokines and chemokines in natural killer, Th1 and B cells (Nakahira et al., 2002; Bossù et al., 2010). IL-18 also activates signaling pathways in microglia, which results in increased caspase-1 expression and matrix metalloproteinases and pro-inflammatory cytokine production (Felderhoff-Mueser et al., 2005). In addition, IL-18 augments Fas ligand expression in glial cells, thereby exacerbating Fas-mediated neuronal cell death in the context of neuroinflammation. IL-18 thus converges two distinct immunological regulatory pathways of inflammatory reactions and cytotoxic effects.

Pyroptosis is a highly inflammatory, programmed form of cell death. It is distinct from necrosis and apoptosis as the pathway is exclusively mediated by activated caspase-1 (Bergsbaken et al., 2009). So far, pyroptosis has been described in both glial cells and neurons (Alfonso-Loeches et al., 2014; Tan et al., 2014; Kim et al., 2015). Pyroptosis causes rapid rupture of the plasma membrane and excessive release of pro-inflammatory cytokines and chemokines such as TNF- $\alpha$, IL- $1 \beta$, IL- 6 and $\mathrm{CX}_{3} \mathrm{C}$-chemokine ligand 3 , which may aggravate inflammatory mediator-induced neuronal death (Fink et al., 2008; Ramesh et al., 2013). As these factors have been shown to mediate the recruitment of other immune cells from peripheral circulation, plenty of leukocytes are attracted to the inflammation sites, and the subsequent inflammatory responses cause severe tissue damage in the CNS under neuropathological conditions (Koedel et al., 2009).

\section{NLRP3 INFLAMMASOME AND NEUROLOGICAL DISEASES}

Aberrant activation of NLRP3 inflammasome signaling has been demonstrated to contribute to pathology in a broad spectrum of neurological diseases (see Table $\mathbf{1}$ ). 
TABLE 1 | Neurological disorders that involve the NLRP3 inflammasome.

\begin{tabular}{|c|c|c|c|}
\hline & Disease & Current animal models & Reference \\
\hline \multirow[t]{4}{*}{ Brain infection } & S. pneumoniae meningitis & Intracisternal inoculation of S. pneumoniae strain (mouse) & $\begin{array}{l}\text { Hoegen et al. (2011), Geldhoff et al. } \\
\text { (2013a), Kim et al. (2015) }\end{array}$ \\
\hline & Japanese encephalitis & Intravenous injection of Japanese Encephalitis virus (mouse) & Kaushik et al. (2012) \\
\hline & Influenza virus infection & Intranasal infection of influenza virus (mouse) & Yu et al. (2014) \\
\hline & HIV/AIDS & $\begin{array}{l}\text { Feline immunodeficiency virus infection (cat); HIV-1 Vpr } \\
\text { transgenic mouse }\end{array}$ & Mamik et al. (2016) \\
\hline \multirow[t]{5}{*}{ Acute injury } & Cerebral ischemia & $\begin{array}{l}\text { Focal cerebral ischemia: transient middle cerebral artery } \\
\text { occlusion (mouse, rat); global cerebral ischemia: bilateral } \\
\text { 4-vessel occlusion (rat) }\end{array}$ & $\begin{array}{l}\text { Fann et al. (2013b), Yang et al. (2014), } \\
\text { Wang et al. (2015), Thakkar et al. (2016) }\end{array}$ \\
\hline & Traumatic brain injury & $\begin{array}{l}\text { Modified Feeney model (mouse); controlled cortical impact } \\
\text { (rat); Blast-induced traumatic brain injury (rat) }\end{array}$ & $\begin{array}{l}\text { Liu et al. (2013), Ma et al. (2016), Lin } \\
\text { et al. (2017) }\end{array}$ \\
\hline & Spinal cord injury & Dorsal root avulsion (rat); spinal cord contusion lesion (rats) & $\begin{array}{l}\text { Ellis et al. (2016), Jiang et al. (2016), } \\
\text { Zendedel et al. (2016) }\end{array}$ \\
\hline & Subarachnoid hemorrhage & Endovascular perforation model (rat) & Li J. et al. (2016), Shao et al. (2016) \\
\hline & Intracerebral hemorrhage & Autologous blood injection (mouse) & Ma et al. (2014), Yang et al. (2015) \\
\hline \multirow[t]{4}{*}{$\begin{array}{l}\text { Neurodegenerative } \\
\text { diseases }\end{array}$} & Alzheimer's disease & $\begin{array}{l}\text { APP/PS1 mouse; TgCRND8 AD mouse; 3xTgAD mouse; } \\
\text { stereotaxic injection of } \boldsymbol{\beta} \text {-amyloid }\end{array}$ & $\begin{array}{l}\text { Heneka et al. (2013), Cho et al. (2014), } \\
\text { Liu et al. (2015), Daniels et al. (2016), } \\
\text { Dempsey et al. (2017) }\end{array}$ \\
\hline & Multiple sclerosis & Experimental autoimmune encephalitis & $\begin{array}{l}\text { Jha et al. (2010), Inoue et al. (2012), } \\
\text { Coll et al. (2015) }\end{array}$ \\
\hline & Amyotrophic lateral sclerosis & SOD1(G93A) mouse model & Johann et al. (2015), Debye et al. (2016) \\
\hline & Prion diseases (remains controversial) & Prion inoculation (mouse) & Nuvolone et al. (2015) \\
\hline
\end{tabular}

\section{Brain Infection}

\section{Bacterial infection}

Streptococcus pneumoniae (S. pneumoniae) causes meningitis when it invades the CSF space. Studies of both murine models and patients have demonstrated that the NLRP3 inflammasome plays a central role in the pathologic progression of pneumococcal meningitis (Hoegen et al., 2011; Geldhoff et al., 2013a). Pneumolysin, a pneumococcal pore-forming cytolysin, induced caspase-1-dependent pyroptotic cell death and IL-1 $\beta$ maturation through ATP-dependent lysosomal destabilization and ROS production (Kim et al., 2015). Excessive NLRP3 inflammasome activation led to extensive inflammatory responses and exacerbated tissue damage in the brain, as well as other adverse outcomes (Wu et al., 2010; Hoegen et al., 2011; Mitchell et al., 2012). Staphylococcus aureus (S. aureus) also induced NLRP3 inflammasome activation in microglia in an ATP- and cathepsin B-dependent manner (Hanamsagar et al., 2011). Moreover, priming microglia with conditioned media from Mycobacterium tuberculosis (Mtb)infected macrophages, in combination with infection with $\mathrm{Mtb}$, instigated robust activation of the NLRP3 inflammasome. Lowering intracellular $\mathrm{K}^{+}$concentrations, lysosomal protease release and mitochondrial ROS generation were suggested to be upstream events of Mtb-induced NLRP3 activation (Lee et al., 2013). Listeria monocytogenes (LM) is the causative agent of several life-threatening diseases, including meningitis and septicemia (Roed et al., 2012; Thønnings et al., 2016). As NLRP3 is one of the major sensors of LM (Warren et al., 2008), it is plausible that NLRP3 inflammasome play a role in the pathology of LM-associated meningitis.

\section{Viral Infection}

Japanese Encephalitis virus (JEV) represents a common cause of acute viral encephalitis. Microglia rapidly respond to JEV infection and secrete several pro- and anti-inflammatory cytokines, including IL-1 $\beta$ and IL-18. JEV triggers NLRP3 inflammasome activation through $\mathrm{K}^{+}$efflux and ROS production, as shown in a murine model and $\mathrm{Bv}-2$ microglial cells (Kaushik et al., 2012). It has been implicated that NLRP3 inflammasome signaling plays a crucial role in host protection during influenza virus challenge; however, prolonged NLRP3 inflammasome activation induces a hyper-inflammatory state and contributes to pathogenesis and mortality (Thomas et al., 2009; McAuley et al., 2013; Pinar et al., 2016; Tate et al., 2016). Additionally, the expression of NLRP3 was up-regulated in murine brains during influenza viral infection ( $\mathrm{Yu}$ et al., 2014). Interestingly, the expression of NLRP3 inflammasomeassociated genes was also increased in the brains of patients with HIV/AIDS (Walsh et al., 2014). An in vivo model of feline immunodeficiency viral infection and HIV-1 Vpr transgenic mice exhibited NLRP3 inflammasome activation with accompanying neuronal loss and neurological disorders (Walsh et al., 2014; Mamik et al., 2016).

\section{CNS Injury}

\section{Cerebral Ischemia}

The innate immune response plays a critical role in the overall pathogenesis of cerebral ischemia injury. Inflammatory cytokines released from activated microglia initiate downstream signaling cascades that eventually lead to neuronal cell loss following acute brain ischemia (Harari and Liao, 2010). NLRP3 protein was found to increase after experimental ischemic stroke, which was concomitant with high IL-1 $\beta$ and IL-18 levels and extensive neuronal and glial cell death (Lammerding et al., 2016). Interference of NLRP3 activation improved cerebral ischemia outcomes, as evidenced by reduced infarction volumes and decreased levels of neurovascular damage (Fann et al., 2013b; Yang et al., 2014). 


\section{Traumatic Injury}

Traumatic brain injury (TBI) and spinal cord injury (SCI) are both debilitating conditions worldwide and are associated with poor prognosis (Levin and Diaz-Arrastia, 2015; Witiw and Fehlings, 2015). In general, they result from insults by an external mechanical force (Xiong et al., 2013), which is characterized by both primary and secondary injury mechanisms. The primary injury is the immediate mechanical disruption of brain tissue. The secondary injury triggers cascades of cellular and molecular events over a prolonged time course (Werner and Engelhard, 2007; Ji et al., 2012). IL-1 $\beta$ has been widely implicated in the progression of TBI and SCI. The protein levels of the NLRP3 inflammasome components were increased in TBI and SCI patients and in murine models (Adamczak et al., 2012; Liu et al., 2013; Zendedel et al., 2016). Notably, ASC neutralization substantially reduced the contusion volume in a rat model of TBI (de Rivero Vaccari et al., 2009). Pannexin1 channel, in addition to being linked to activation of the NLRP3 inflammasome, serves as a cell death effector during neuronal pyroptosis, which makes it a potential therapeutic target (Adamczak et al., 2014).

\section{Hemorrhagic Stroke}

Intracerebral hemorrhage $(\mathrm{ICH})$ is a devastating stroke subtype (Keep et al., 2012). The pathophysiology of ICH is characterized by the infiltration of systemic immune cells, the activation of microglia and the production of pro-inflammatory cytokines such as IL-1 $\beta$ (Wang and Doré, 2007). The expression of NLRP3 was increased in a mouse model of $\mathrm{ICH}$, and the inhibition of NLRP3 attenuated neuroinflammation and improved neuronal function, which indicates the involvement of NLRP3 inflammasome in the pathogenesis of ICH (Ma et al., 2014; Yang et al., 2015; Yuan et al., 2015). ROS and the $\mathrm{P} 2 \mathrm{X}$ purinergic receptor 7 (P2X7R) pathway may play roles in NLRP3 activation during ICH (Ma et al., 2014; Feng et al., 2015).

Subarachnoid hemorrhage $(\mathrm{SAH})$ is a fatal cerebrovascular disease with the highest mortality among all stroke subtypes (Bian et al., 2012; Keep et al., 2012). Early brain injury, which is highlighted by neuroinflammation, represents a key mechanism of SAH development (Sehba et al., 2012). NLRP3 inflammasome was found to be activated in a rat SAH model (Li J. et al., 2016; Shao et al., 2016). Pharmacological inhibition of P2X7R ameliorated brain edema and neurological deficits, which indicates a mechanism of the P2X7R pathway in NLRP3 activation after SAH (Chen et al., 2013).

\section{Neurodegenerative Diseases}

Neurodegenerative diseases are always accompanied by chronic neuroinflammation with the excessive production of IL-1 $\beta$ and IL-18 pro-inflammatory cytokines, which has detrimental consequences for brain structure and function. The NLRP3 inflammasome is of particular importance in the development of inflammatory responses. To date, a pathogenic role of the NLRP3 inflammasome has been shown in several neurodegenerative diseases including $\mathrm{AD}, \mathrm{MS}$ and amyotrophic lateral sclerosis (ALS). Whether the NLRP3 inflammasome contributes to the pathogenesis of Prion diseases remains debated.
AD

The expression of NLRP3 and caspase-1 is substantially increased in the brains of $\mathrm{AD}$ patients (Heneka et al., 2013; Saresella et al., 2016). It has become evident that extracellular deposition of $\beta$-amyloid $(A \beta)$ peptides in senile plaques is the initiating event in $\mathrm{AD}$. $\mathrm{A} \beta$ drives the release of mature IL- $1 \beta$ via activation of the NLRP3 inflammasome in microglia (Halle et al., 2008; Parajuli et al., 2013). NLRP3 or caspase-1 deficiency substantially attenuates spatial memory impairment and enhances $\mathrm{A} \beta$ clearance in $\mathrm{AD}$ transgenic mice (Heneka et al., 2013). According to a candidate gene study conducted among northern Han Chinese, two functional single-nucleotide polymorphisms (SNPs) in the NLRP3 gene (rs2027432 and rs10754558) had synergistic effects on late-onset $\mathrm{AD}$ risk (Tan et al., 2013). Moreover, CARD8 protein suppresses NLRP3 activity, and another study indicates that the p.C10X polymorphism of the CARD8 gene (rs2043211) predisposes people to AD (Fontalba et al., 2008).

\section{MS}

MS is characterized by the demyelination of axons and chronic inflammation; experimental autoimmune encephalitis (EAE) is the most widely used rodent model for MS. The expression levels of caspase-1, IL- $1 \beta$ and IL-18 were increased in MS plaques and cells from MS patients (Huang et al., 2004; Inoue et al., 2012). NLRP3-deficient mice exhibited resistance to EAE, as evidenced by reduced demyelination and astrogliosis in the spinal cord (Gris et al., 2010). It has been suggested that the NLRP3 inflammasome is likely involved in EAE pathogenesis through the induction of chemokine-mediated recruitment of immune cells (Inoue et al., 2012). However, recent studies have shown that pertussis toxin, which is commonly injected as an adjuvant to increase EAE incidence, induced activation of a pyrin-dependent inflammasome (Dumas et al., 2014; Barclay and Shinohara, 2017), Therefore, the inflammasome sensor involved in MS/EAE might be not restricted to NLRP3.

\section{ALS}

Mutations in human superoxide dismutase 1 lead to the formation of toxic misfolded protein aggregates, which play an important role in the pathogenesis ALS (Tsuda et al., 1994; Ioannides et al., 2016). Increased NLRP3, ASC, IL-1 $\beta$, IL-18 and active caspase-1 levels were detected in both human ALS tissue and in murine models (Johann et al., 2015; Debye et al., 2016). Transactive response DNA-binding protein-43 (TDP-43) is considered a major component of intraneuronal aggregates in ALS patients (Arai et al., 2006). TDP-43 instigated NLRP3 inflammasome activation in microglia, which resulted in a pro-inflammatory signaling that is detrimental to motor neurons (Zhao et al., 2015).

\section{Prion Diseases}

Prion diseases are caused by the conversion of cellular prion protein $\left(\mathrm{PrP}^{\mathrm{C}}\right)$ to the pathological isoform $\mathrm{PrP}^{\mathrm{Sc}}$ through conformational changes (Shi F. et al., 2015). Aggregated $\mathrm{PrP}^{\mathrm{Sc}}$ peptides lead to the activation of microglia and astrocytes, which results in the release of pro-inflammatory cytokines 
and neurotoxic factors (Tribouillard-Tanvier et al., 2009). PrP exposure up-regulated NLRP3 and ASC expression in microglia, and silencing of NLRP3 or ASC significantly reduced IL-1 $\beta$ production (Shi F. et al., 2012). However, a recent in vivo study using NLRP3- or ASC-deficient mice inoculated with scrapie prions demonstrated that NLRP3 and ASC were not involved in prion pathogenesis (Nuvolone et al., 2015). This discrepancy might be attributed to the different prion proteins used in these studies and the strain-specific features of prion diseases (Tixador et al., 2010; Ayers et al., 2011). More studies on other forms of prion diseases are needed to verify the involvement of the NLRP3 inflammasome.

\section{TARGETING THE NLRP3 INFLAMMASOME FOR THE TREATMENT OF NEUROLOGICAL DISEASES}

The relevance of the NLRP3 inflammasome in human CNS pathologies has led to research on the possibilities of pharmacologically targeting the NLRP3 signaling pathways. To date, several advances have been made in the identification of exogenous compounds that may block IL-1 signaling or serve as inhibitors of NLRP3 inflammasome activation (White et al., 2017; see Figure 3); however, most compounds are in the early stages of development.

\section{Anti-IL-1 Therapy}

Currently, anti-IL-1 therapies including interleukin-1 receptor antagonists (IL-1Ra) such as anakinra and specific monoclonal antibodies such as canakinumab have been approved for use in patients with auto-inflammatory disorders (KuemmerleDeschner et al., 2011). IL-1Ra administration reduced ischemic brain injury in a murine stroke model; however, it failed to exhibit long-term beneficial effects (Paolicelli et al., 2012). Anakinra is thought to have a preponderance for cryopyrin-associated periodic syndrome (CAPS)-associated neurologic disease because of its better CNS penetration. In addition, several other applications that target IL-1 or IL-1R are also under development (Dinarello et al., 2012). Despite their notable efficacy, anti-IL-1 drugs cannot resolve inflammasome-associated symptoms. Nevertheless, caspase1-mediated pathways such as pyroptosis also drive disease pathology. These findings suggest that the direct blockade of inflammasome activation instead of merely neutralizing its downstream cytokines may be advantageous for controlling unwanted inflammatory reactions. Moreover, anti-IL-1 therapies are expensive and most of them may not readily penetrate tissues such as the brain.

\section{Small Molecule Inhibitors of NLRP3}

Compounds with a sulfonylurea moiety appear to specifically inhibit activation of the NLRP3 inflammasome in the activation

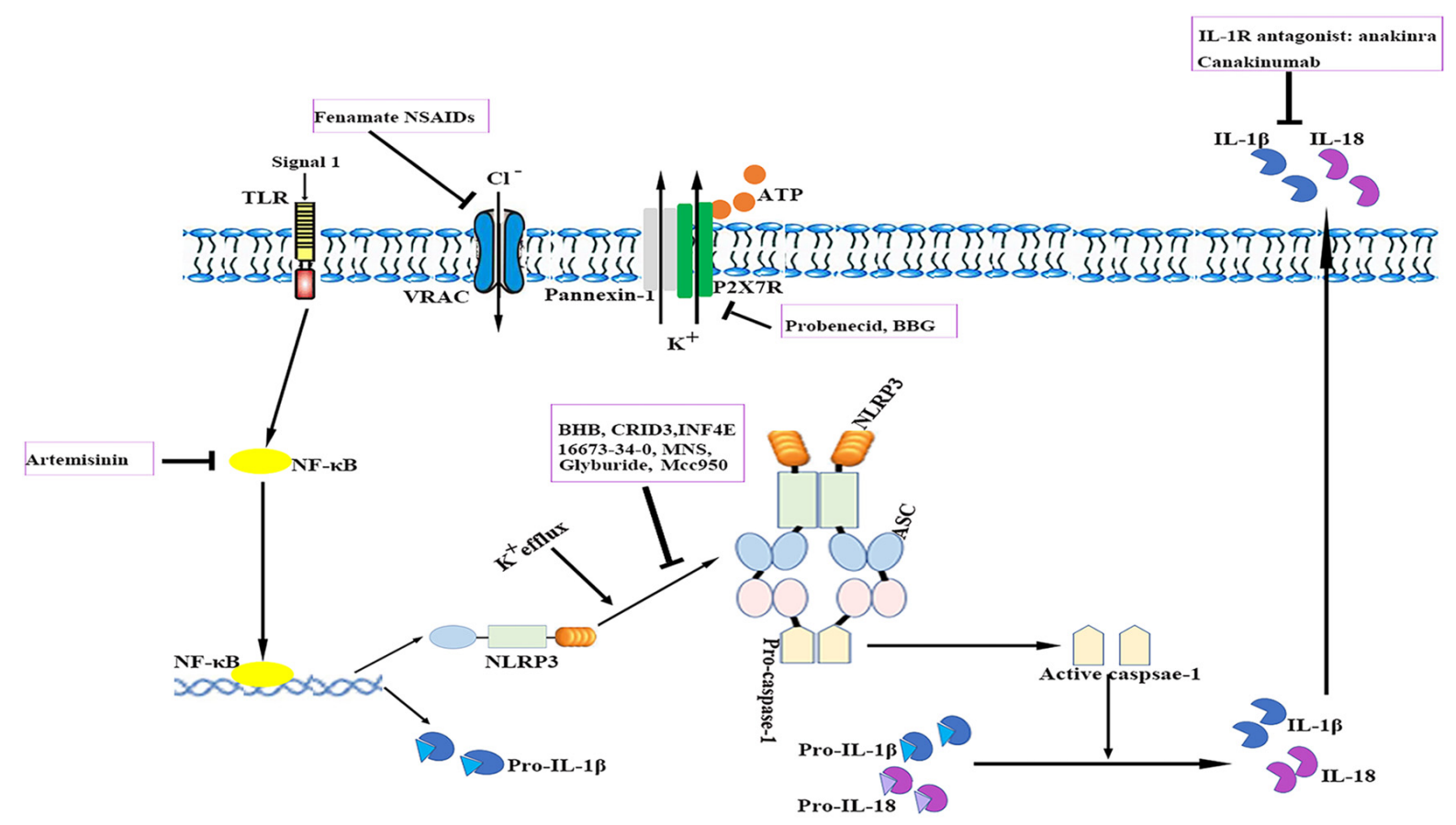

FIGURE 3 | Therapeutic approaches to targeting the NLRP3 inflammasome. The cartoon depicts the schematic mode of various therapeutic approaches described in detail in the text. Several steps in NLRP3 activation and the IL-1 pathway have been identified as targets for anti-neuroinflammatory therapies. ASC, apoptosis-related speck-like protein containing a caspase recruitment domain; ATP, adenosine triphosphate; BBG, brilliant blue G; BHB, $\beta$-hydroxybutyrate; IL, interleukin; IL-1R, interleukin-1 receptor; MNS, 3,4-methylenedioxy- $\beta$-nitrostyrene; NF- $\mathrm{B}$, nuclear factor- $\mathrm{B}$; NLRP3, nucleotide-binding oligomerization domain-, leucine-rich repeat- and pyrin domain-containing 3; P2X7R, P2X purinergic receptor 7; TLR, Toll-like receptor. 
stage without affecting the NF- $\mathrm{B}$ signaling-dependent priming stage (Lamkanfi et al., 2009; Coll et al., 2015). Glyburide was the first identified sulfonylurea moiety-containing drug to exhibit NLRP3-inhibitory activity in vitro; however, the required in vivo dose is associated with hypoglycemic effects. MCC950, a small-molecule compound that shares similarities with sulfonylurea, was shown to block ASC oligomerization induced by NLRP3, which makes it a highly potent and selective NLRP3 inhibitor. It effectively attenuated the inflammatory response in murine EAE models and ex vivo human samples (Coll et al., 2015). Its role in other neurological diseases requires additional investigation. Additionally, 16673-34-0, an intermediate substrate in glyburide synthesis, exhibited no effect on glucose metabolism and has been demonstrated to ameliorate myocardial ischemia/reperfusion (I/R) injury by inhibiting the formation of the NLRP3 inflammasome (Marchetti et al., 2014).

The ketone metabolite $\beta$-hydroxybutyrate (BHB) was discovered to suppress NLRP3 inflammasome activation by inhibiting NLRP3-ASC oligomerization (Youm et al., 2015). Experiments showed that $\mathrm{BHB}$ decreased $\mathrm{K}^{+}$efflux and endoplasmic reticulum stress (Youm et al., 2015; Bae et al., 2016). Furthermore, BHB is transported to brain parenchyma and plays a neuroprotective role under several pathological conditions (Orhan et al., 2015; Xie et al., 2015).

A cysteinyl leukotriene receptor antagonist, which had been initially incorrectly termed as CRID3, was found to prevent caspase-1 activation in response to NLRP3 activators via direct inhibition of ASC oligomerization (Coll et al., 2011, 2015).

INF4E is a newly synthesized compound that directly inhibits NLRP3 ATPase and specifically suppresses NLRP3 inflammasome activation (Cocco et al., 2014). It was shown to be protective against NLRP3-involved myocardial $\mathrm{I} / \mathrm{R}$ in a rat model (Mastrocola et al., 2016). Further rigorous investigations are needed to evaluate the effects of INF4E on neurological diseases and its side effects.

3,4-methylenedioxy- $\beta$-nitrostyrene (MNS), a novel tyrosine kinase inhibitor, was reported to specifically and potently inhibit NLRP3 by directly targeting its NOD and LRR domain ( $\mathrm{He}$ and Amer, 2014). According to a recent study, MNS prevented wound progression and improved healing in an experimental burn model (Xiao et al., 2016). The potent effects and minimal cytotoxicity of MNS make it an attractive candidate for the treatment of neurological diseases; however, studies investigating the role of MNS in the CNS are lacking (Hsieh et al., 2010).

\section{Other Compounds that Target Specific Pathways}

Artemisinin, a well-established antimalarial drug, has been verified to exert anti-inflammatory effects via inhibition of the NF- $\kappa \mathrm{B}$ signaling pathway. Artemisinin treatment also reduced the neuritic plaque burden and NLRP3 inflammasome activity in an AD transgenic mouse model (Shi et al., 2013). Studies have shown that artemisinin induces various side effects such as neurotoxicity, cardiotoxicity, embryotoxicity and allergic reactions when administered long-term (Efferth and Kaina, 2010; Li and Hickman, 2011).

The ATP-gated receptor P2X7R has been implicated in activation of the NLRP3 inflammasome (Deplano et al., 2013). P2X7R antagonist brilliant blue $\mathrm{G}$ (BBG) alleviated inflammation and improved neurological functions in a rodent model of SAH (Chen et al., 2013). BBG can penetrate the BBB at relatively low doses (Diaz-Hernandez et al., 2012). However, the use of $\mathrm{P} 2 \mathrm{X} 7 \mathrm{R}$ antagonists is controversial as these receptors are located in various cell types under pathological conditions and they may induce undesirable off-target effects (Franke et al., 2004).

Probenecid, an FDA-approved drug for gout and hyperuricemia treatment, is a specific Pannexin 1 channel blocker (Silverman et al., 2009). Probenecid inhibited NLRP3 activation in cultured neurons and astrocytes by providing a high extracellular concentration of $\mathrm{K}^{+}$and decreased caspase-1 expression in the brains of aged rats (Mawhinney et al., 2011; Jian et al., 2016).

A recent study reported that fenamate non-steroidal anti-inflammatory drugs (NSAIDs), including flufenamic acid and mefenamic acid, were neuroprotective in rodent models of AD (Daniels et al., 2016). Fenamates selectively inhibited NLRP3 by blocking volume-regulated anion channels (VRAC) in macrophages (Daniels et al., 2016). Fenamate NSAIDs target both VRAC/NLRP3 and cyclooxygenases, which makes them more efficacious than those targeting a single point in one inflammatory pathway. However, fenamate NSAIDs are associated with CNS toxicity, gastrointestinal adverse effects, nephrotoxicity, metabolic acidosis and prolongation of prothrombin time (Kingswell, 1981; Redmond, 1981; Frank et al., 1983; Court and Volans, 1984; Kamour et al., 2016). It is important to reassess the benefit-risk profile of fenamate NSAIDs for treating NLRP3-associated disorders.

\section{OUTSTANDING QUESTIONS}

To date, several hurdles that require further investigation remain. Because the mechanisms of NLRP3 activation are differentially regulated at the cell and tissue levels (Toldo et al., 2015), it is necessary to characterize each step of the NLRP3 inflammasome cascades in specific cell types and brain regions under different pathological contexts. Additionally, the potential roles of NLRP3 signaling in the regulation of specific cell interactions that are involved in neuroinflammation remain to be elucidated.

\section{CONCLUSIONS AND FUTURE DIRECTIONS}

Major advances in the understanding of inflammasomes and inflammasome-mediated disorders have been made in the past decade. A spectrum of inflammatory responses has been associated with CNS pathological circumstances; thus, inflammasome activation likely exerts strong influences on various neurological diseases. Insufficient activation of inflammasome causes the host to become vulnerable to PAMPs and DAMPs; nevertheless, excessive inflammasome activation 
causes unfavorable outcomes in diverse diseases (Rathinam et al., 2012). Thus, the manipulation of a balanced and effective inflammasome-mediated inflammatory response is of paramount importance.

Recent years, Cre-lox recombination-mediated neurogenetics has been developed as a useful technique to generate cell-specific gene knock-outs (KO) and knock-ins (Witten et al., 2011). Conditional autophagy gene KO mice have been recently generated by breeding autophagy-deficient mice with specific Cre drivers to investigate the regulatory role of autophagy in NLRP3 inflammasome activation in microglia (Cho et al., 2014). It is plausible to generate microglia/astrocyte conditional NLRP3 KO and knock-in mice through a similar genetic approach to study cell-specific interactions.

\section{REFERENCES}

Abo-Ouf, H., Hooper, A. W., White, E. J., van Rensburg, H. J., Trigatti, B. L., and Igdoura, S. A. (2013). Deletion of tumor necrosis factor- $\alpha$ ameliorates neurodegeneration in Sandhoff disease mice. Hum. Mol. Genet. 22, 3960-3975. doi: $10.1093 / \mathrm{hmg} / \mathrm{ddt} 250$

Adamczak, S., Dale, G., de Rivero Vaccari, J. P., Bullock, M. R., Dietrich, W. D., and Keane, R. W. (2012). Inflammasome proteins in cerebrospinal fluid of brain-injured patients as biomarkers of functional outcome: clinical article. J. Neurosurg. 117, 1119-1125. doi: 10.3171/2012.9.JNS 12815

Adamczak, S. E., de Rivero Vaccari, J. P., Dale, G., Brand, F. J. III., Nonner, D., Bullock, M. R., et al. (2014). Pyroptotic neuronal cell death mediated by the AIM2 inflammasome. J. Cereb. Blood Flow Metab. 34, 621-629. doi: $10.1038 /$ jcbfm.2013.236

Agostini, L., Martinon, F., Burns, K., McDermott, M. F., Hawkins, P. N., and Tschopp, J. (2004). NALP3 forms an IL-1 $\beta$-processing inflammasome with increased activity in Muckle-Wells autoinflammatory disorder. Immunity 20, 319-325. doi: 10.1016/s1074-7613(04)00046-9

Alfonso-Loeches, S., Ureña-Peralta, J. R., Morillo-Bargues, M. J., OliverDe La Cruz, J., and Guerri, C. (2014). Role of mitochondria ROS generation in ethanol-induced NLRP3 inflammasome activation and cell death in astroglial cells. Front. Cell. Neurosci. 8:216. doi: 10.3389/fncel.2014. 00216

Alvarez, J. I., Dodelet-Devillers, A., Kebir, H., Ifergan, I., Fabre, P. J., Terouz, S., et al. (2011). The Hedgehog pathway promotes blood-brain barrier integrity and CNS immune quiescence. Science 334, 1727-1731. doi: 10.1126/science. 1206936

Anderson, M. A., Ao, Y., and Sofroniew, M. V. (2014). Heterogeneity of reactive astrocytes. Neurosci. Lett. 565, 23-29. doi: 10.1016/j.neulet.2013.12.030

Anderson, J. P., Mueller, J. L., Rosengren, S., Boyle, D. L., Schaner, P., Cannon, S. B., et al. (2004). Structural, expression and evolutionary analysis of mouse CIAS1. Gene 338, 25-34. doi: 10.1016/j.gene.2004.05.002

Aoki, E., Yano, R., Yokoyama, H., Kato, H., and Araki, T. (2009). Role of nuclear transcription factor kappa B (NF-kappaB) for MPTP (1-methyl-4-phenyl1,2,3,6-tetrahyropyridine)-induced apoptosis in nigral neurons of mice. Exp. Mol. Pathol. 86, 57-64. doi: 10.1016/j.yexmp.2008.10.004

Arai, T., Hasegawa, M., Akiyama, H., Ikeda, K., Nonaka, T., Mori, H., et al. (2006). TDP-43 is a component of ubiquitinpositive tau-negative inclusions in frontotemporal lobar degeneration and amyotrophic lateral sclerosis. Biochem. Biophys. Res. Commun. 351, 602-611. doi: 10.1016/j.bbrc.2006. 10.093

Arend, W. P., Palmer, G., and Gabay, C. (2008). IL-1, IL-18 and IL-33 families of cytokines. Immunol. Rev. 223, 20-38. doi: 10.1111/j.1600-065X.2008. 00624.x

Ayers, J. I., Schutt, C. R., Shikiya, R. A., Aguzzi, A., Kincaid, A. E., and Bartz, J. C. (2011). The strain-encoded relationship between PrP replication, stability and processing in neurons is predictive of the incubation period of disease. PLoS Pathog. 7:e1001317. doi: 10.1371/journal.ppat.1001317

\section{AUTHOR CONTRIBUTIONS}

LS and LP made equal contribution to this work, performed literature review and drafted the article. SY revised and critically appraised the manuscript for intellectual content. YS and YW contributed to the revision and edition of the manuscript. All authors read and approved the final manuscript.

\section{ACKNOWLEDGMENTS}

This work was supported by the grants from the National Natural Science Foundation of China (81270018, 81471202 and $81271270)$. The funders had no role in the content of the text, decision to publish, or preparation of the manuscript.

Bae, H. R., Kim, D. H., Park, M. H., Lee, B., Kim, M. J., Lee, E. K., et al. (2016) $\beta$-Hydroxybutyrate suppresses inflammasome formation by ameliorating endoplasmic reticulum stress via AMPK activation. Oncotarget 7, 66444-66454. doi: 10.18632/oncotarget.12119

Barclay, W., and Shinohara, M. L. (2017). Inflammasome activation in multiple sclerosis and experimental autoimmune encephalomyelitis (EAE). Brain Pathol. 27, 213-219. doi: 10.1111/bpa.12477

Barreto, G. E., Gonzalez, J., Torres, Y., and Morales, L. (2011). Astrocytic-neuronal crosstalk: implications for neuroprotection from brain injury. Neurosci. Res. 71, 107-113. doi: 10.1016/j.neures.2011.06.004

Bauernfeind, F. G., Horvath, G., Stutz, A., Alnemri, E. S., MacDonald, K.,

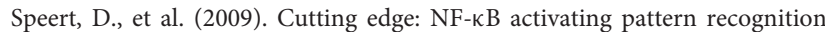
and cytokine receptors license NLRP3 inflammasome activation by regulating NLRP3 expression. J. Immunol. 183, 787-791. doi: 10.4049/jimmunol. 0901363

Becher, B., Prat, A., and Antel, J. P. (2000). Brain-immune connection: immuno-regulatory properties of CNS-resident cells. Glia 29, 293-304 doi: 10.1002/(SICI)1098-1136(20000215)29:4<293::AID-GLIA1>3.3.CO;2-1

Bergsbaken, T., Fink, S. L., and Cookson, B. T. (2009). Pyroptosis: host cell death and inflammation. Nat. Rev. Microbiol. 7, 99-109. doi: 10.1038/nrmicro2070

Bian, L. H., Liu, Y. F., Nichols, L. T., Wang, C. X., Wang, Y. L., Liu, G. F., et al. (2012). Epidemiology of subarachnoid hemorrhage, patterns of management and outcomes in China: a hospital-based multicenter prospective study. CNS Neurosci. Ther. 18, 895-902. doi: 10.1111/cns.12001

Bossù, P., Ciaramella, A., Salani, F., Vanni, D., Palladino, I., Caltagirone, C., et al. (2010). Interleukin-18, from neuroinflammation to Alzheimer's disease. Curr Pharm. Des. 16, 4213-4224. doi: 10.2174/138161210794519147

Brown, A. M., and Ransom, B. R. (2007). Astrocyte glycogen and brain energy metabolism. Glia 55, 1263-1267. doi: 10.1002/glia.20557

Bruchard, M., Mignot, G., Derangère, V., Chalmin, F., Chevriaux, A., Végran, F., et al. (2013). Chemotherapy-triggered cathepsin B release in myeloid-derived suppressor cells activates the Nlrp3 inflammasome and promotes tumor growth. Nat. Med. 19, 57-64. doi: 10.1038/nm.2999

Byrnes, K. R., and Faden, A. I. (2007). Role of cell cycle proteins in CNS injury. Neurochem. Res. 32, 1799-1807. doi: 10.1007/s11064-007-9312-2

Cannon, J. G. (2000). Inflammatory cytokines in nonpathological states. News Physiol. Sci. 15, 298-303.

Chen, X., He, W. T., Hu, L., Li, J., Fang, Y., Wang, X., et al. (2016). Pyroptosis is driven by non-selective gasdermin-D pore and its morphology is different from MLKL channel-mediated necroptosis. Cell Res. 26, 1007-1020. doi: 10.1038/cr. 2016.100

Chen, S., Ma, Q., Krafft, P. R., Hu, Q., Rolland, W. II., Sherchan, P., et al. (2013). $\mathrm{P} 2 \mathrm{X} 7 \mathrm{R} /$ cryopyrin inflammasome axis inhibition reduces neuroinflammation after SAH. Neurobiol. Dis. 58, 296-307. doi: 10.1016/j.nbd.2013.06.011

Cherry, J. D., Olschowka, J. A., and O’Banion, M. K. (2014). Neuroinflammation and M2 microglia: the good, the bad and the inflamed. J. Neuroinflammation 11:98. doi: 10.1186/1742-2094-11-98

Cho, M. H., Cho, K., Kang, H. J., Jeon, E. Y., Kim, H. S., Kwon, H. J., et al. (2014). Autophagy in microglia degrades extracellular $\beta$-amyloid fibrils and regulates 
the NLRP3 inflammasome. Autophagy 10, 1761-1775. doi: 10.4161/auto. 29647

Choi, D. Y., Liu, M., Hunter, R. L., Cass, W. A., Pandya, J. D., Sullivan, P. G., et al. (2009). Striatal neuroinflammation promotes Parkinsonism in rats. PLoS One 4:e5482. doi: 10.1371/journal.pone.0005482

Chuang, Y. T., Lin, Y. C., Lin, K. H., Chou, T. F., Kuo, W. C., Yang, K. T., et al. (2011). Tumor suppressor death-associated protein kinase is required for full IL-1 $\beta$ production. Blood 117, 960-970. doi: 10.1182/blood-2010-08303115

Cocco, M., Garella, D., Di Stilo, A., Borretto, E., Stevanato, L., Giorgis, M., et al. (2014). Electrophilic warhead-based design of compounds preventing NLRP3 inflammasome-dependent pyroptosis. J. Med. Chem. 57, 10366-10382. doi: 10.1021/jm501072b

Coll, R. C., Robertson, A., Butler, M., Cooper, M., and O’Neill, L. A. (2011). The cytokine release inhibitory drug CRID3 targets ASC oligomerisation in the NLRP3 and AIM2 inflammasomes. PLoS One 6:e29539. doi: 10.1371/journal. pone.0029539

Coll, R. C., Robertson, A. A., Chae, J. J., Higgins, S. C., Muñoz-Planillo, R., Inserra, M. C., et al. (2015). A small-molecule inhibitor of the NLRP3 inflammasome for the treatment of inflammatory diseases. Nat. Med. 21, 248-255. doi: 10.1038/nm.3806

Court, H., and Volans, G. N. (1984). Poisoning after overdose with non-steroidal anti-inflammatory drugs. Adverse Drug React. Acute Poisoning Rev. 3, 1-21.

Cregg, J. M., DePaul, M. A., Filous, A. R., Lang, B. T., Tran, A., and Silver, J. (2014). Functional regeneration beyond the glial scar. Exp. Neurol. 253, 197-207. doi: 10.1016/j.expneurol.2013.12.024

Daniels, M. J., Rivers-Auty, J., Schilling, T., Spencer, N. G., Watremez, W., Fasolino, V., et al. (2016). Fenamate NSAIDs inhibit the NLRP3 inflammasome and protect against Alzheimer's disease in rodent models. Nat. Commun. 7:12504. doi: $10.1038 /$ ncomms 12504

David, S., and Kroner, A. (2011). Repertoire of microglial and macrophage responses after spinal cord injury. Nat. Rev. Neurosci. 12, 388-399. doi: 10.1038/nrn3053

de Almeida, L., Khare, S., Misharin, A. V., Patel, R., Ratsimandresy, R. A., Wallin, M. C., et al. (2015). The PYRIN domain-only protein POP1 inhibits inflammasome assembly and ameliorates inflammatory disease. Immunity 43, 264-276. doi: 10.1016/j.immuni.2015.07.018

de Jong, B. A., Huizinga, T. W., Bollen, E. L., Uitdehaag, B. M., Bosma, G. P., van Buchem, M. A., et al. (2002). Production of IL-1 $\beta$ and IL-1Ra as risk factors for susceptibility and progression of relapse-onset multiple sclerosis. J. Neuroinflammation 126, 172-179. doi: 10.1016/s0165-5728(02)00056-5

de Rivero Vaccari, J. P., Brand, F. III., Adamczak, S., Lee, S. W., Perez-Barcena, J., Wang, M. Y., et al. (2016). Exosome-mediated inflammasome signaling after central nervous system injury. J. Neurochem. 136, 39-48. doi: 10.1111/jnc. 13036

de Rivero Vaccari, J. P., Lotocki, G., Alonso, O. F., Bramlett, H. M., Dietrich, W. D., and Keane, R. W. (2009). Therapeutic neutralization of the NLRP1 inflammasome reduces the innate immune response and improves histopathology after traumatic brain injury. J. Cereb. Blood Flow Metab. 29, 1251-1261. doi: 10.1038/jcbfm.2009.46

Debye, B., Schmülling, L., Zhou, L., Rune, G., Beyer, C., and Johann, S. (2016). Neurodegeneration and NLRP3 inflammasome expression in the anterior thalamus of SOD1(G93A) ALS mice. Brain Pathol. doi: 10.1111/bpa.12467 [Epub ahead of print].

Demento, S. L., Eisenbarth, S. C., Foellmer, H. G., Platt, C., Caplan, M. J., Mark Saltzman, W., et al. (2009). Inflammasome-activating nanoparticles as modular systems for optimizing vaccine efficacy. Vaccine 27, 3013-3021. doi: 10.1016/j. vaccine.2009.03.034

Dempsey, C., Rubio Araiz, A., Bryson, K. J., Finucane, O., Larkin, C., Mills, E. L., et al. (2017). Inhibiting the NLRP3 inflammasome with MCC950 promotes non-phlogistic clearance of amyloid- $\beta$ and cognitive function in APP/PS1 mice. Brain Behav. Immun. 61, 306-316. doi: 10.1016/j.bbi.2016.12.014

Deplano, S., Cook, H. T., Russell, R., Franchi, L., Schneiter, S., Bhangal, G., et al. (2013). P2X7 receptor-mediated Nlrp3-inflammasome activation is a genetic determinant of macrophage-dependent crescentic glomerulonephritis. J. Leukoc. Biol. 93, 127-134. doi: 10.1189/jlb.0612284

Diaz-Hernandez, J. I., Gomez-Villafuertes, R., León-Otegui, M., HontecillasPrieto, L., Del Puerto, A., Trejo, J. L., et al. (2012). In vivo P2X7 inhibition reduces amyloid plaques in Alzheimer's disease through GSK3 $\beta$ and secretases. Neurobiol. Aging 33, 1816-1828. doi: 10.1016/j.neurobiolaging.2011. 09.040

Dinarello, C. A., Simon, A., and van der Meer, J. W. (2012). Treating inflammation by blocking interleukin-1 in a broad spectrum of diseases. Nat. Rev. Drug Discov. 11, 633-652. doi: 10.1038/nrd3800

Ding, J., Wang, K., Liu, W., She, Y., Sun, Q., Shi, J., et al. (2016). Pore-forming activity and structural autoinhibition of the gasdermin family. Nature 573, 111-116. doi: 10.1038/nature18590

Dowds, T. A., Masumoto, J., Zhu, L., Inohara, N., and Núñez, G. (2004). Cryopyrin-induced interleukin $1 \beta$ secretion in monocytic cells: enhanced activity of disease-associated mutants and requirement for ASC. J. Biol. Chem. 279, 21924-21928. doi: 10.1074/jbc.M401178200

Dumas, A., Amiable, N., de Rivero Vaccari, J. P., Chae, J. J., Keane, R. W., Lacroix, S., et al. (2014). The inflammasome pyrin contributes to pertussis toxin-induced IL-1 $\beta$ synthesis, neutrophil intravascular crawling and autoimmune encephalomyelitis. PLoS Pathog. 10:e1004150. doi: 10.1371/journal.ppat.1004150

Duncan, J. A., Bergstralh, D. T., Wang, Y., Willingham, S. B., Ye, Z., Zimmermann, A. G., et al. (2007). Cryopyrin/NALP3 binds ATP/dATP, is an ATPase and requires ATP binding to mediate inflammatory signaling. Proc. Natl. Acad. Sci. U S A 104, 8041-8046. doi: 10.1073/pnas. 0611496104

Duncan, J. A., Gao, X., Huang, M. T., O'Connor, B. P., Thomas, C. E., Willingham, S. B., et al. (2009). Neisseria gonorrhoeae activates the proteinase cathepsin $\mathrm{B}$ to mediate the signaling activities of the NLRP3 and ASC-containing inflammasome. J. Immunol. 182, 6460-6469. doi: 10.4049/jimmunol.0802696

Efferth, T., and Kaina, B. (2010). Toxicity of the antimalarial artemisinin and its dervatives. Crit. Rev. Toxicol. 40, 405-421. doi: 10.3109/10408441003610571

Ellis, A., Grace, P. M., Wieseler, J., Favret, J., Springer, K., Skarda, B., et al. (2016). Morphine amplifies mechanical allodynia via TLR4 in a rat model of spinal cord injury. Brain Behav. Immun. 58, 348-356. doi: 10.1016/j.bbi.2016. 08.004

Elmore, M. R., Burton, M. D., Conrad, M. S., Rytych, J. L., Van Alstine, W. G., and Johnson, R. W. (2014). Respiratory viral infection in neonatal piglets causes marked microglia activation in the hippocampus and deficits in spatial learning. J. Neurosci. 34, 2120-2129. doi: 10.1523/JNEUROSCI. 2180-13.2014

Fann, D. Y., Lee, S. Y., Manzanero, S., Chunduri, P., Sobey, C. G., and Arumugam, T. V. (2013a). Pathogenesis of acute stroke and the role of inflammasomes. Ageing Res. Rev. 12, 941-966. doi: 10.1016/j.arr.2013. 09.004

Fann, D. Y., Lee, S. Y., Manzanero, S., Tang, S. C., Gelderblom, M., Chunduri, P., et al. (2013b). Intravenous immunoglobulin suppresses NLRP1 and NLRP3 inflammasome-mediated neuronal death in ischemic stroke. Cell Death Dis. 4:e790. doi: 10.1038/cddis.2013.326

Felderhoff-Mueser, U., Schmidt, O. I., Oberholzer, A., Bührer, C., and Stahel, P. F. (2005). IL-18: a key player in neuroinflammation and neurodegeneration? Trends Neurosci. 28, 487-493. doi: 10.1016/j.tins.2005.06.008

Fellner, L., Irschick, R., Schanda, K., Reindl, M., Klimaschewski, L., Poewe, W., et al. (2013). Toll-like receptor 4 is required for $\alpha$-synuclein dependent activation of microglia and astroglia. Glia 61, 349-360. doi: 10.1002/glia. 22437

Feng, L., Chen, Y., Ding, R., Fu, Z., Yang, S., Deng, X., et al. (2015). P2X7R blockade prevents NLRP3 inflammasome activation and brain injury in a rat model of intracerebral hemorrhage: involvement of peroxynitrite. J. Neuroinflammation 12:190. doi: 10.1186/s12974-015-0409-2

Ferrante, C. J., Pinhal-Enfield, G., Elson, G., Cronstein, B. N., Hasko, G., Outram, S., et al. (2013). The adenosine-dependent angiogenic switch of macrophages to an M2-like phenotype is independent of interleukin-4 receptor alpha (IL-4R $\alpha$ ) signaling. Inflammation 36, 921-931. doi: 10.1007/s10753-0139621-3

Ferrari, C. C., Depino, A. M., Prada, F., Muraro, N., Campbell, S., Podhajcer, O., et al. (2004). Reversible demyelination, blood-brain barrier breakdown and pronounced neutrophil recruitment induced by chronic IL-1 expression in the brain. Am. J. Pathol. 165, 1827-1837. doi: 10.1016/s0002-9440(10) 63438-4 
Feske, S., Skolnik, E. Y., and Prakriya, M. (2012). Ion channels and transporters in lymphocyte function and immunity. Nat. Rev. Immunol. 12, 532-547. doi: $10.1038 /$ nri3233

Fink, S. L., Bergsbaken, T., and Cookson, B. T. (2008). Anthrax lethal toxin and Salmonella elicit the common cell death pathway of caspase-1-dependent pyroptosis via distinct mechanisms. Proc. Natl. Acad. Sci. U S A 105, 4312-4317. doi: 10.1073/pnas.0707370105

Fogal, B., Li, J., Lobner, D., McCullough, L. D., and Hewett, S. J. (2007). System $\mathrm{x}_{\mathrm{C}}{ }^{-}$activity and astrocytes are necessary for interleukin-1 $\beta$-mediated hypoxic neuronal injury. J. Neurosci. 27, 10094-10105. doi: 10.1523/JNEUROSCI.245907.2007

Fontalba, A., Gutiérrez, O., Llorca, J., Mateo, I., Berciano, J., FernándezLuna, J. L., et al. (2008). Deficiency of CARD8 is associated with increased Alzheimer's disease risk in women. Dement. Geriatr. Cogn. Disord. 26, 247-250. doi: 10.1159/000160956

Franco, R., and Fernández-Suárez, D. (2015). Alternatively activated microglia and macrophages in the central nervous system. Prog. Neurobiol. 131, 65-86. doi: 10.1016/j.pneurobio.2015.05.003

Franke, H., Günther, A., Grosche, J., Schmidt, R., Rossner, S., Reinhardt, R., et al. (2004). P2X7 receptor expression after ischemia in the cerebral cortex of rats. J. Neuropathol. Exp. Neurol. 63, 686-699. doi: 10.1093/jnen/63.7.686

Frank, J. J., Wightkin, W. T., and Hubner, J. W. (1983). Acute toxicity of nonsteroidal antiinflammatory agents: seizure following a mefenamic acid overdose. Drug Intell. Clin. Pharm. 17, 204-205. doi: 10.1177/106002808301700309

Fu, R., Shen, Q., Xu, P., Luo, J. J., and Tang, Y. (2014). Phagocytosis of microglia in the central nervous system diseases. Mol. Neurobiol. 49, 1422-1434. doi: 10.1007/s12035-013-8620-6

Geissmann, F., Gordon, S., Hume, D. A., Mowat, A. M., and Randolph, G. J. (2010). Unravelling mononuclear phagocyte heterogeneity. Nat. Rev. Immunol. 10, 453-460. doi: 10.1038/nri2784

Geldhoff, M., Mook-Kanamori, B. B., Brouwer, M. C., Troost, D., Leemans, J. C., Flavell, R. A., et al. (2013a). Inflammasome activation mediates inflammation and outcome in humans and mice with pneumococcal meningitis. BMC Infect. Dis. 13:358. doi: 10.1186/1471-2334-13-358

Geldhoff, M., Mook-Kanamori, B. B., Brouwer, M. C., Valls Seron, M., Baas, F., van der Ende, A., et al. (2013b). Genetic variation in inflammasome genes is associated with outcome in bacterial meningitis. Immunogenetics 65, 9-16. doi: 10.1007/s00251-012-0653-x

Gosselin, D., and Rivest, S. (2007). Role of IL-1 and TNF in the brain: twenty years of progress on a Dr. Jekyll/Mr. Hyde duality of the innate immune system. Brain Behav. Immun. 21, 281-289. doi: 10.1016/j.bbi.2006.12.004

Gris, D., Ye, Z., Iocca, H. A., Wen, H., Craven, R. R., Gris, P., et al. (2010). NLRP3 plays a critical role in the development of experimental autoimmune encephalomyelitis by mediating Th1 and Th17 responses. J. Immunol. 185, 974-981. doi: 10.4049/jimmunol.0904145

Halle, A., Hornung, V., Petzold, G. C., Stewart, C. R., Monks, B. G., Reinhecke, L. T., et al. (2008). The NALP3 inflammasome is involved in the innate immune response to amyloid- $\beta$. Nat. Immunol. 9, 857-865. doi: $10.1038 /$ ni.1636

Hanamsagar, R., Torres, V., and Kielian, T. (2011). Inflammasome activation and IL-1 $\beta / \mathrm{IL}-18$ processing are influenced by distinct pathways in microglia. J. Neurochem. 119, 736-748. doi: 10.1111/j.1471-4159.2011.07481.x

Harari, O. A., and Liao, J. K. (2010). NF-кB and innate immunity in ischemic stroke. Ann. N Y Acad. Sci. 1207, 32-40. doi: 10.1111/j.1749-6632.2010.05735.x

He, Y., and Amer, A. O. (2014). Microbial modulation of host apoptosis and pyroptosis. Front. Cell. Infect. Microbiol. 4:83. doi: 10.3389/fcimb.2014.00083

He, Y., Zeng, M. Y., Yang, D., Motro, B., and Núñez, G. (2016). NEK7 is an essential mediator of NLRP3 activation downstream of potassium efflux. Nature 530, 354-357. doi: 10.1038/nature16959

Heneka, M. T., and O'Banion, M. K. (2007). Inflammatory processes in Alzheimer's disease. J. Neuroimmunol. 184, 69-91. doi: 10.1016/j.jneuroim. 2006.11.017

Heneka, M. T., Kummer, M. P., and Latz, E. (2014). Innate immune activation in neurodegenerative disease. Nat. Rev. Immunol. 14, 463-477. doi: 10.1038/nri3705

Heneka, M. T., Kummer, M. P., Stutz, A., Delekate, A., Schwartz, S., VieiraSaecker, A., et al. (2013). NLRP3 is activated in Alzheimer' disease and contributes to pathology in APP/PS1 mice. Nature 493, 674-678. doi: $10.1038 /$ nature 11729

Hernandez-Cuellar, E., Tsuchiya, K., Hara, H., Fang, R., Sakai, S., Kawamura, I., et al. (2012). Cutting edge: nitric oxide inhibits the NLRP3 inflammasome. J. Immunol. 189, 5113-5117. doi: 10.4049/jimmunol.1202479

Hoegen, T., Tremel, N., Klein, M., Angele, B., Wagner, H., Kirschning, C., et al. (2011). The NLRP3 inflammasome contributes to brain injury in pneumococcal meningitis and is activated through ATPdependent lysosomal cathepsin B release. J. Immunol. 187, 5540-5551. doi: 10.4049/jimmunol. 1100790

Hoffman, H. M., Scott, P., Mueller, J. L., Misaghi, A., Stevens, S., Yancopoulos, G. D., et al. (2010). Role of the leucine-rich repeat domain of cryopyrin/NALP3 in monosodium urate crystal-induced inflammation in mice. Arthritis Rheum. 62, 2170-2179. doi: 10.1002/art.27456

Hornung, V., Bauernfeind, F., Halle, A., Samstad, E. O., Kono, H., Rock, K. L., et al. (2008). Silica crystals and aluminum salts activate the NALP3 inflammasome through phagosomal destabilization. Nat. Immunol. 9, 847-856. doi: 10.1038/ni.1631

Hsieh, P. W., Chang, Y. T., Chuang, W. Y., Shih, H. C., Chiang, S. Z., and Wu, C. C. (2010). The synthesis and biologic evaluation of anti-platelet and cytotoxic $\beta$-nitrostyrenes. Bioorg. Med. Chem. 18, 7621-7627. doi: 10.1016/j.bmc.2010. 08.039

Hu, X., Liu, G., Hou, Y., Shi, J., Zhu, L., Jin, D., et al. (2012). Induction of M2-like macrophages in recipient NOD-scid mice by allogeneic donor $\mathrm{CD} 4^{+} \mathrm{CD} 25^{+}$ regulatory T cells. Cell. Mol. Immunol. 9, 464-472. doi: 10.1038/cmi.2012.47

$\mathrm{Hu}$, S., Sheng, W. S., Ehrlich, L. C., Peterson, P. K., and Chao, C. C. (2000). Cytokine effects on glutamate uptake by human astrocytes. Neuroimmunomodulation 7, 153-159. doi: 10.1159/000026433

Huang, W. X., Huang, P., and Hillert, J. (2004). Increased expression of caspase- 1 and interleukin-18 in peripheral blood mononuclear cells in patients with multiple sclerosis. Mult. Scler. 10, 482-487. doi: 10.1191/1352458504ms 1071 oa

Inoue, M., Williams, K. L., Gunn, M. D., and Shinohara, M. L. (2012). NLRP3 inflammasome induces chemotactic immune cell migration to the CNS in experimental autoimmune encephalomyelitis. Proc. Natl. Acad. Sci. U S A 109, 10480-10485. doi: 10.1073/pnas.1201836109

Ioannides, Z. A., Henderson, R. D., Robertson, T., Davis, M., and McCombe, P. A. (2016). When does ALS start? A novel SOD-1 p.Gly142Arg mutation causing motor neurone disease with prominent premorbid cramps and spasms. J. Neurol. Neurosurg. Psychiatry 87, 1031-1032. doi: 10.1136/jnnp-2015-3 11582

Ito, U., Nagasao, J., Kawakami, E., and Oyanagi, K. (2007). Fate of disseminated dead neurons in the cortical ischemic penumbra: ultrastructure indicating a novel scavenger mechanism of microglia and astrocytes. Stroke 38, 2577-2583. doi: 10.1161/STROKEAHA.107.484394

Ito, M., Shichita, T., Okada, M., Komine, R., Noguchi, Y., Yoshimura, A., et al. (2015). Bruton's tyrosine kinase is essential for NLRP3 inflammasome activation and contributes to ischaemic brain injury. Nat. Commun. 6:7360. doi: $10.1038 /$ ncomms 8360

Jha, S., Srivastava, S. Y., Brickey, W. J., Iocca, H., Toews, A., Morrison, J. P., et al. (2010). The inflammasome sensor, NLRP3, regulates CNS inflammation and demyelination via caspase-1 and interleukin-18. J. Neurosci. 30, 15811-15820. doi: 10.1523/JNEUROSCI.4088-10.2010

Ji, J., Kline, A. E., Amoscato, A., Samhan-Arias, A. K., Sparvero, L. J., Tyurin, V. A. et al. (2012). Lipidomics identifies cardiolipin oxidation as a mitochondrial target for redox therapy of brain injury. Nat. Neurosci. 15, 1407-1413. doi: 10.1038/nn.3195

Jian, Z., Ding, S., Deng, H., Wang, J., Yi, W., Wang, L., et al. (2016). Probenecid protects against oxygen-glucose deprivation injury in primary astrocytes by regulating inflammasome activity. Brain Res. 1643, 123-129. doi: 10.1016/j. brainres.2016.05.002

Jiang, W., Huang, Y., He, F., Liu, J., Li, M., Sun, T., et al. (2016). Dopamine D1 receptor agonist A-68930 inhibits NLRP3 inflammasome activation, controls Inflammation, and alleviates histopathology in a rat model of spinal cord injury. Spine (Phila Pa 1976) 41, E330-E334. doi: 10.1097/BRS. 0000000000001287

Johann, S., Heitzer, M., Kanagaratnam, M., Goswami, A., Rizo, T., Weis, J., et al. (2015). NLRP3 inflammasome is expressed by astrocytes in the SOD1 mouse 
model of ALS and in human sporadic ALS patients. Glia 63, 2260-2273. doi: 10.1002/glia.22891

Juliana, C., Fernandes-Alnemri, T., Kang, S., Farias, A., Qin, F., and Alnemri, E. S. (2012). Non-transcriptional priming and deubiquitination regulate NLRP3 inflammasome activation. J. Biol. Chem. 287, 36617-36622. doi: 10.1074/jbc.M112.407130

Kamour, A., Crichton, S., Cooper, G., Lupton, D. J., Eddleston, M., Vale, J. A., et al. (2016). Central nervous system toxicity of mefenamic acid overdose compared with other NSAIDs: an analysis of cases reported to the United Kingdom National Poisons Information Service. Br. J. Clin. Pharmacol. doi: 10.1111/bcp. 13169 [Epub ahead of print].

Kanneganti, T. D., Body-Malapel, M., Amer, A., Park, J. H., Whitfield, J., Franchi, L., et al. (2006a). Critical role for Cryopyrin/Nalp3 in activation of caspase-1 in response to viral infection and double-stranded RNA. J. Biol. Chem. 281, 36560-36568. doi: 10.1074/jbc.M607594200

Kanneganti, T. D., Ozören, N., Body-Malapel, M., Amer, A., Park, J. H., Franchi, L., et al. (2006b). Bacterial RNA and small antiviral compounds activate caspase-1 through cryopyrin/Nalp3. Nature 440, 233-236. doi: 10.1038/nature04517

Karmakar, M., Katsnelson, M. A., Dubyak, G. R., and Pearlman, E. (2016). Neutrophil P2X7 receptors mediate NLRP3 inflammasomedependent IL-1 $\beta$ secretion in response to ATP. Nat. Commun. 7:10555. doi: $10.1038 /$ ncomms 10555

Karve, I. P., Taylor, J. M., and Crack, P. J. (2016). The contribution of astrocytes and microglia to traumatic brain injury. Br. J. Pharmacol. 173, 692-702. doi: $10.1111 /$ bph.13125

Kaushal, V., Dye, R., Pakavathkumar, P., Foveau, B., Flores, J., Hyman, B., et al. (2015). Neuronal NLRP1 inflammasome activation of Caspase-1 coordinately regulates inflammatory interleukin-1- $\beta$ production and axonal degeneration-associated Caspase-6 activation. Cell Death Differ. 22, 1676-1686. doi: $10.1038 /$ cdd.2015.16

Kaushik, D. K., Gupta, M., Kumawat, K. L., and Basu, A. (2012). NLRP3 inflammasome: key mediator of neuroinflammation in murine Japanese encephalitis. PLoS One 7:e32270. doi: 10.1371/journal.pone.0032270

Keep, R. F., Hua, Y., and Xi, G. (2012). Intracerebral haemorrhage: mechanisms of injury and therapeutic targets. Lancet Neurol. 11, 720-731. doi: 10.1016/s14744422(12)70104-7

Keller, M., Rüegg, A., Werner, S., and Beer, H. D. (2008). Active caspase-1 is a regulator of unconventional protein secretion. Cell 32, 818-831. doi: 10.1016/j. cell.2007.12.040

Kettenmann, H., Hanisch, U.-K., Noda, M., and Verkhratsky, A. (2011). Physiology of microglia. Physiol. Rev. 91, 461-553. doi: 10.1152/physrev.00011. 2010

Kierdorf, K., Erny, D., Goldmann, T., Sander, V., Schulz, C., Perdiguero, E. G., et al. (2013). Microglia emerge from erythromyeloid precursors via Pu.1- and Irf8-dependent pathways. Nat. Neurosci. 16, 273-280. doi: 10.1038/nn.3318

Kim, J.-Y., Paton, J. C., Briles, D. E., Rhee, D.-K., and Pyo, S. (2015). Streptococcus pneumoniae induces pyroptosis through the regulation of autophagy in murine microglia. Oncotarget 6, 44161-44178. doi: 10.18632/oncotarget.6592

Kingswell, R. S. (1981). Mefenamic acid overdose. Lancet 2:307. doi: 10.1016/s0140-6736(81)90554-7

Koedel, U., Frankenberg, T., Kirschnek, S., Obermaier, B., Häcker, H., Paul, R., et al. (2009). Apoptosis is essential for neutrophil functional shutdown and determines tissue damage in experimental pneumococcal meningitis. PLoS Pathog. 5:e1000461. doi: 10.1371/journal.ppat.1000461

Kuemmerle-Deschner, J. B., Hachulla, E., Cartwright, R., Hawkins, P. N., Tran, T. A., Bader-Meunier, B., et al. (2011). Two-year results from an open-label, multicentre, phase III study evaluating the safety and efficacy of canakinumab in patients with cryopyrin-associated periodic syndrome across different severity phenotypes. Ann. Rheum. Dis. 70, 2095-2102. doi: 10.1136/ard.2011.152728

Kumar, A., Barrett, J. P., Alvarez-Croda, D. M., Stoica, B. A., Faden, A. I., and Loane, D. J. (2016). NOX2 drives M1-like microglial/macrophage activation and neurodegeneration following experimental traumatic brain injury. Brain Behav. Immun. 58, 291-309. doi: 10.1016/j.bbi.2016.07.158

Kumar, H., Kawai, T., and Akira, S. (2011). Pathogen recognition by the innate immune system. Int. Rev. Immunol. 30, 16-34. doi: 10.3109/08830185.2010. 529976
Lalancette-Hébert, M., Gowing, G., Simard, A., Weng, Y. C., and Kriz, J. (2007). Selective ablation of proliferating microglial cells exacerbates ischemic injury in the brain. J. Neurosci. 27, 2596-2605. doi: 10.1523/JNEUROSCI.536006.2007

Lamkanfi, M., Mueller, J. L., Vitari, A. C., Misaghi, S., Fedorova, A., Deshayes, K., et al. (2009). Glyburide inhibits the Cryopyrin/Nalp3 inflammasome. J. Cell Biol. 187, 61-70. doi: 10.1083/jcb.200903124

Lammerding, L., Slowik, A., Johann, S., Beyer, C., and Zendedel, A. (2016). Post-stroke inflammasome expression and regulation in the peri-infarct area by gonadal steroids after transient focal ischemia in the rat brain. Neuroendocrinology 103, 460-475. doi: 10.1159/000439435

Lazovic, J., Basu, A., Lin, H.-W., Rothstein, R. P., Krady, J. K., Smith, M. B., et al. (2005). Neuroinflammation and both cytotoxic and vasogenic edema are reduced in interleukin-1 type 1 receptor-deficient mice conferring neuroprotection. Stroke 36, 2226-2231. doi: 10.1161/01.str.0000182255. $08162.6 \mathrm{a}$

Lee, H. M., Kang, J., Lee, S. J., and Jo, E. K. (2013). Microglial activation of the NLRP3 inflammasome by the priming signals derived from macrophages infected with mycobacteria. Glia 61, 441-452. doi: 10.1002/glia. 22448

Lee, G. S., Subramanian, N., Kim, A. I., Aksentijevich, I., Goldbach-Mansky, R., Sacks, D. B., et al. (2012). The calcium-sensing receptor regulates the NLRP3 inflammasome through $\mathrm{Ca}^{2+}$ and cAMP. Nature 492, 123-127. doi: 10.1038 /nature11588

Levin, H. S., and Diaz-Arrastia, R. R. (2015). Diagnosis, prognosis, and clinical management of mild traumatic brain injury. Lancet Neurol. 14, 506-517. doi: 10.1016/s1474-4422(15)00002-2

Li, J., Chen, J., Mo, H., Chen, J., Qian, C., Yan, F., et al. (2016). Minocycline protects against NLRP3 inflammasome-induced inflammation and p53-associated apoptosis in early brain injury after subarachnoid hemorrhage. Mol. Neurobiol. 53, 2668-2678. doi: 10.1007/s12035-015-9318-8

Li, Q., and Hickman, M. (2011). Toxicokinetic and toxicodynamic (TK/TD) evaluation to determine and predict the neurotoxicity of artemisinins. Toxicology 279, 1-9. doi: 10.1016/j.tox.2010.09.005

Li, D., Wang, C., Yao, Y., Chen, L., Liu, G., Zhang, R., et al. (2016). mTORC1 pathway disruption ameliorates brain inflammation following stroke via a shift in microglia phenotype from M1 type to M2 type. FASEB J. 30, 3388-3399. doi: 10.1096/fj.201600495r

Licastro, F., Pedrini, S., Caputo, L., Annoni, G., Davis, L. J., Ferri, C., et al. (2000). Increased plasma levels of interleukin-1, interleukin-6 and $\alpha$-1-antichymotrypsin in patients with Alzheimer's disease: peripheral inflammation or signals from the brain? J. Neuroimmunol. 103, 97-102. doi: 10.1016/s0165-5728(99)00226-x

Liepinsh, E., Barbals, R., Dahl, E., Sharipo, A., Staub, E., and Otting, G. (2003). The death-domain fold of the ASC PYRIN domain, presenting a basis for PYRIN/PYRIN recognition. J. Mol. Biol. 332, 1155-1163. doi: 10.1016/j.jmb. 2003.07.007

Lin, C., Chao, H., Li, Z., Xu, X., Liu, Y., Bao, Z., et al. (2017). Omega-3 fatty acids regulate NLRP3 inflammasome activation and prevent behavior deficits after traumatic brain injury. Exp. Neurol. 290, 115-122. doi: 10.1016/j.expneurol. 2017.01.005

Liu, B., Le, K. X., Park, M. A., Wang, S., Belanger, A. P., Dubey, S., et al. (2015). In vivo detection of age- and disease-related Increases in neuroinflammation by 18F-GE180 TSPO MicroPET Imaging in wild-type and Alzheimer's transgenic mice. J. Neurosci. 35, 15716-15730. doi: 10.1523/JNEUROSCI.099615.2015

Liu, H.-D., Li, W., Chen, Z.-R., Hu, Y.-C., Zhang, D.-D., Shen, W., et al. (2013). Expression of the NLRP3 inflammasome in cerebral cortex after traumatic brain injury in a rat model. Neurochem. Res. 38, 2072-2083. doi: 10.1007/s11064-013-1115-Z

Liu, X., Zhang, Z., Ruan, J., Pan, Y., Magupalli, V. G., Wu, H., et al. (2016). Inflammasome-activated gasdermin D causes pyroptosis by forming membrane pores. Nature 535, 153-158. doi: 10.1038/nature18629

Loane, D. J., and Byrnes, K. R. (2010). Role of microglia in neurotrauma. Neurotherapeutics 7, 366-377. doi: 10.1016/j.nurt.2010.07.002

Lu, B., Nakamura, T., Inouye, K., Li, J., Tang, Y., Lundbäck, P., et al. (2012). Novel role of PKR in inflammasome activation and HMGB1 release. Nature 488, 670-674. doi: 10.1038/nature 11290 
Lu, M., Sun, X. L., Qiao, C., Liu, Y., Ding, J. H., and Hu, G. (2014). Uncoupling protein 2 deficiency aggravates astrocytic endoplasmic reticulum stress and nod-like receptor protein 3 inflammasome activation. Neurobiol. Aging 35, 421-430. doi: 10.1016/j.neurobiolaging.2013.08.015

Ma, Q., Chen, S., Hu, Q., Feng, H., Zhang, J. H., and Tang, J. (2014). NLRP3 inflammasome contributes to inflammation after intracerebral hemorrhage. Ann. Neurol. 75, 209-219. doi: 10.1002/ana.24070

Ma, J., Xiao, W., Wang, J., Wu, J., Ren, J., Hou, J., et al. (2016). Propofol inhibits NLRP3 inflammasome and attenuates blast-Induced traumatic brain injury in rats. Inflammation 39, 2094-2103. doi: 10.1007/s10753-0160446-8

Mamik, M. K., Hui, E., Branton, W. G., McKenzie, B. A., Chisholm, J., Cohen, E. A., et al. (2016). HIV-1 viral protein R activates NLRP3 inflammasome in microglia: implications for HIV-1 associated neuroinflammation. J. Neuroimmune Pharmacol. doi: 10.1007/s11481-0169708-3 [Epub ahead of print].

Marchetti, C., Chojnacki, J., Toldo, S., Mezzaroma, E., Tranchida, N., Rose, S. W., et al. (2014). A novel pharmacologic inhibitor of the NLRP3 inflammasome limits myocardial injury after ischemia-reperfusion in the mouse. J. Cardiovasc. Pharmacol. 63, 316-322. doi: 10.1097/FJC.000000000 0000053

Mariathasan, S., Weiss, D. S., Newton, K., McBride, J., O’Rourke, K., RooseGirma, M., et al. (2006). Cryopyrin activates the inflammasome in response to toxins and ATP. Nature 440, 228-232. doi: 10.1038/nature04515

Marina-García, N., Franchi, L., Kim, Y. G., Miller, D., McDonald, C., Boons, G. J., et al. (2008). Pannexin-1-mediated intracellular delivery of muramyl dipeptide induces caspase-1 activation via cryopyrin/NLRP3 independently of Nod2. J. Immunol. 180, 4050-4057. doi: 10.4049/jimmunol.180. 6.4050

Martinon, F., Burns, K., and Tschopp, J. (2002). The inflammasome: a molecular platform triggering activation of inflammatory caspases and processing of proIL- $\beta$. Mol. Cell 10, 417-426. doi: 10.1016/S1097-2765(02) 00599-3

Martinon, F., Pétrilli, V., Mayor, A., Tardivel, A., and Tschopp, J. (2006). Goutassociated uric acid crystals activate the NALP3 inflammasome. Nature 440, 237-241. doi: 10.1038/nature04516

Masters, S. L., Dunne, A., Subramanian, S. L., Hull, R. L., Tannahill, G. M., Sharp, F. A., et al. (2010). Activation of the NLRP3 inflammasome by islet amyloid polypeptide provides a mechanism for enhanced IL- $1 \beta$ in type 2 diabetes. Nat. Immunol. 11, 897-904. doi: 10.1038/ni.1935

Mastrocola, R., Penna, C., Tullio, F., Femminò, S., Nigro, D., Chiazza, F., et al. (2016). Pharmacological inhibition of NLRP3 inflammasome attenuates myocardial ischemia/reperfusion injury by activation of RISK and mitochondrial pathways. Oxid. Med. Cell. Longev. 2016:5271251. doi: $10.1155 / 2016 / 5271251$

Masumoto, J., Taniguchi, S., Ayukawa, K., Sarvotham, H., Kishino, T., Niikawa, N., et al. (1999). ASC, a novel 22-kDa protein, aggregates during apoptosis of human promyelocytic leukemia HL-60 cells. J. Biol. Chem. 274, 33835-33838. doi: 10.1074/jbc.274.48.33835

Mawhinney, L. J., de Rivero Vaccari, J. P., Dale, G. A., Keane, R. W., and Bramlett, H. M. (2011). Heightened inflammasome activation is linked to age-related cognitive impairment in Fischer 344 rats. BMC Neurosci. 12:123. doi: 10.1186/1471-2202-12-123

McAfoose, J., and Baune, B. T. (2009). Evidence for a cytokine model of cognitive function. Neurosci. Biobehav. Rev. 33, 355-366. doi: 10.1016/j.neubiorev.2008. 10.005

McAuley, J. L., Tate, M. D., MacKenzie-Kludas, C. J., Pinar, A., Zeng, W., Stutz, A., et al. (2013). Activation of the NLRP3 inflammasome by IAV virulence protein PB1-F2 contributes to severe pathophysiology and disease. PLoS Pathog. 9:e1003392. doi: 10.1371/journal.ppat.1003392

Meissner, F., Molawi, K., and Zychlinsky, A. (2010). Mutant superoxide dismutase 1 -induced IL-1 $\beta$ accelerates ALS pathogenesis. Proc. Natl. Acad. Sci. U S A 107, 13046-13050. doi: 10.1073/pnas.1002396107

Meng, G., Grabiec, A., Vallon, M., Ebe, B., Hampel, S., Bessler, W., et al. (2003). Cellular recognition of tri-/di-palmitoylated peptides is independent from a domain encompassing the N-terminal seven leucine-rich repeat (LRR)/LRRlike motifs of TLR2. J. Biol. Chem. 278, 39822-39829. doi: 10.1074/jbc. m304766200
Michell-Robinson, M. A., Touil, H., Healy, L. M., Owen, D. R., Durafourt, B. A., Bar-Or, A., et al. (2015). Roles of microglia in brain development, tissue maintenance and repair. Brain 138, 1138-1159. doi: 10.1093/brain/ awv066

Mishra, B. B., Rathinam, V. A., Martens, G. W., Martinot, A. J., Kornfeld, H., Fitzgerald, K. A., et al. (2013). Nitric oxide controls the immunopathology of tuberculosis by inhibiting NLRP3 inflammasome-dependent processing of IL-1 $\beta$. Nat. Immunol. 14, 52-60. doi: 10.1038/ni.2474

Mitchell, A. J., Yau, B., McQuillan, J. A., Ball, H. J., Too, L. K., Abtin, A., et al. (2012). Inflammasome-dependent IFN- $\gamma$ drives pathogenesis in Streptococcus pneumoniae meningitis. J. Immunol. 189, 4970-4980. doi: 10.4049/jimmunol. 1201687

Miwa, T., Furukawa, S., Nakajima, K., Furukawa, Y., and Kohsaka, S. (1997). Lipopolysaccharide enhances synthesis of brain-derived neurotrophic factor in cultured rat microglia. J. Neurosci. Res. 50, 1023-1029. doi: 10.1002/(SICI)10974547(19971215)50:6<1023::AID-JNR13>3.3.CO;2-S

Moss, D. W., and Bates, T. E. (2001). Activation of murine microglial cell lines by lipopolysaccharide and interferon- $\gamma$ causes NO-mediated decreases in mitochondrial and cellular function. Eur. J. Neurosci. 13, 529-538. doi: 10.1046/j.1460-9568.2001.01418.x

Murakami, T., Ockinger, J., Yu, J., Byles, V., McColl, A., Hofer, A. M., et al. (2012). Critical role for calcium mobilization in activation of the NLRP3 inflammasome. Proc. Natl. Acad. Sci. U S A 109, 11282-11287. doi: 10.1073/pnas.1117765109

Nakahira, M., Ahn, H. J., Park, W. R., Gao, P., Tomura, M., Park, C. S., et al. (2002). Synergy of IL-12 and IL-18 for IFN- $\gamma$ gene expression: IL-12-induced STAT4 contributes to IFN- $\gamma$ promoter activation by up-regulating the binding activity of IL-18-induced activator protein 1. J. Immunol. 168, 1146-1153. doi: 10.4049/jimmunol.168.3.1146

Nayak, D., Roth, T. L., and McGavern, D. B. (2014). Microglia development and function. Annu. Rev. Immunol. 32, 367-402. doi: 10.1146/annurev-immunol032713-120240

Newman, Z. L., Crown, D., Leppla, S. H., and Moayeri, M. (2010). Anthrax lethal toxin activates the inflammasome in sensitive rat macrophages. Biochem. Biophys. Res. Commun. 398, 785-789. doi: 10.1016/j.bbrc.2010. 07.039

Nuvolone, M., Sorce, S., Schwarz, P., and Aguzzi, A. (2015). Prion pathogenesis in the absence of NLRP3/ASC inflammasomes. PLoS One 10:e117208. doi: 10.1371 /journal.pone. 0117208

O'Connor, W. J., Harton, J. A., Zhu, X., Linhoff, M. W., and Ting, J. P. (2003). Cutting edge: CIAS1/cryopyrin/PYPAF1/NALP3/CATERPILLER 1.1 is an inducible inflammatory mediator with NF- $\kappa$ B suppressive properties. J. Immunol. 171, 6329-6333. doi: 10.4049/jimmunol.171. 12.6329

Orhan, N., Ugur Yilmaz, C., Ekizoglu, O., Ahishali, B., Kucuk, M., Arican, N., et al. (2015). Effects of $\beta$-hydroxybutyrate on brain vascular permeability in rats with traumatic brain injury. Brain Res. 1631, 113-126. doi: 10.1016/j.brainres.2015. 11.038

Orihuela, R., McPherson, C. A., and Harry, G. J. (2016). Microglial M1/M2 polarization and metabolic states. Br. J. Pharmacol. 173, 649-665. doi: 10.1111/bph.13139

Paolicelli, R. C., Bolasco, G., Pagani, F., Maggi, L., Scianni, M., Panzanelli, P., et al. (2012). Synaptic pruning by microglia is necessary for normal brain development. Science 333, 1456-1458. doi: 10.1126/science. 1202529

Parajuli, B., Sonobe, Y., Horiuchi, H., Takeuchi, H., Mizuno, T., and Suzumura, A. (2013). Oligomeric amyloid $\beta$ induces IL-1 $\beta$ processing via production of ROS implication in Alzheimer's disease. Cell Death Dis. 4:e975. doi: 10.1038/cddis. 2013.503

Pekny, M., and Nilsson, M. (2005). Astrocyte activation and reactive gliosis. Glia 50, 427-434. doi: 10.1002/glia.20207

Perea, G., Navarrete, M., and Araque, A. (2009). Tripartite synapses: astrocytes process and control synaptic information. Trends Neurosci. 32, 421-431. doi: 10.1016/j.tins.2009.05.001

Perea, G., Sur, M., and Araque, A. (2014). Neuron-glia networks: integral gear of brain function. Front. Cell. Neurosci. 8:378. doi: 10.3389/fncel.2014.00378

Pétrilli, V., Papin, S., Dostert, C., Mayor, A., Martinon, F., and Tschopp, J. (2007). Activation of the NALP3 inflammasome is triggered by low intracellular 
potassium concentration. Cell Death Differ. 14, 1583-1589. doi: 10.1038/sj.cdd. 4402195

Pinar, A., Dowling, J. K., Bitto, N. J., Robertson, A. B., Latz, E., Stewart, C. R., et al. (2016). PB1-F2 derived from avian influenza a virus H7N9 induces inflammation via activation of the NLRP3 inflammasome. J. Biol. Chem. 292, 826-836. doi: 10.1074/jbc.M116.756379

Py, B. F., Kim, M. S., Vakifahmetoglu-Norberg, H., and Yuan, J. (2013). Deubiquitination of NLRP3 by BRCC3 critically regulates inflammasome activity. Mol. Cell 49, 331-338. doi: 10.1016/j.molcel.2012.11.009

Qin, M., Landriscina, A., Rosen, J. M., Wei, G., Kao, S., Olcott, W., et al. (2015). Nitric Oxide-releasing nanoparticles prevent propionibacterium acnesinduced inflammation by both clearing the organism and inhibiting microbial stimulation of the innate immune response. J. Invest. Dermatol. 135, 2723-2731. doi: 10.1038/jid.2015.277

Ramesh, G., MacLean, A. G., and Philipp, M. T. (2013). Cytokines and chemokines at the crossroads of neuroinflammation, neurodegeneration, and neuropathic pain. Mediators Inflamm. 2013:480739. doi: 10.1155/2013/480739

Rathinam, V. A., Jiang, Z., Waggoner, S. N., Sharma, S., Cole, L. E., Waggoner, L., et al. (2010). The AIM2 inflammasome is essential for host defense against cytosolic bacteria and DNA viruses. Nat. Immunol. 11, 395-402. doi: 10.1038/ni.1864

Rathinam, V. A., Vanaja, S. K., and Fitzgerald, K. A. (2012). Regulation of inflammasome signaling. Nat. Immunol. 13, 333-342. doi: 10.1038/ni.2237

Redmond, A. D. (1981). Dyskinesia induced by mefanimic acid? J. R. Soc. Med. 74, 558-559.

Ribes, S., Ebert, S., Czesnik, D., Regen, T., Zeug, A., Bukowski, S., et al. (2009). Toll-like receptor prestimulation increases phagocytosis of Escherichia coli DH5alpha and Escherichia coli K1 strains by murine microglial cells. Infect. Immun. 77, 557-564. doi: 10.1128/IAI.00903-08

Rock, R. B., Gekker, G., Hu, S., Sheng, W. S., Cheeran, M., Lokensgard, J. R., et al. (2004). Role of microglia in central nervous system infections. Clin. Microbiol. Rev. 17, 942-964. doi: 10.1128/CMR.17.4.942-964.2004

Roed, C., Engsig, F. N., Omland, L. H., Skinhoj, P., and Obel, N. (2012). Longterm mortality in patients diagnosed with Listeria monocytogenes meningitis: a Danish nationwide cohort study. J. Infect. 64, 34-40. doi: 10.1016/j.jinf.2011. 10.003

Rosenzweig, H. L., Planck, S. R., and Rosenbaum, J. T. (2011). NLRs in immune privileged sites. Curr. Opin. Pharmacol. 11, 423-428. doi: 10.1016/j.coph.2011. 07.002

Saijo, K., Crotti, A., and Glass, C. K. (2013). Regulation of microglia activation and deactivation by nuclear receptors. Glia 61, 104-111. doi: 10.1002/glia.22423

Saitoh, T., Fujita, N., Jang, M. H., Uematsu, S., Yang, B. G., Satoh, T., et al. (2008). Loss of the autophagy protein Atg16L1 enhances endotoxininduced IL-1 $\beta$ production. Nature 456, 264-268. doi: 10.1038/nature 07383

Saresella, M., La Rosa, F., Piancone, F., Zoppis, M., Marventano, I., Calabrese, E., et al. (2016). The NLRP3 and NLRP1 inflammasomes are activated in Alzheimer's disease. Mol. Neurodegener. 11:23. doi: 10.1186/s13024-0160088-1

Schmid-Burgk, J. L., Chauhan, D., Schmidt, T., Ebert, T. S., Reinhardt, J., Endl, E., et al. (2016). A genome-wide CRISPR (Clustered Regularly Interspaced Short Palindromic Repeats) screen identifies NEK7 as an essential component of NLRP3 inflammasome activation. J. Biol. Chem. 291, 103-109. doi: 10.1074/jbc. C115.700492

Sehba, F. A., Hou, J., Pluta, R. M., and Zhang, J. H. (2012). The importance of early brain injury after subarachnoid hemorrhage. Prog. Neurobiol. 97, 14-37. doi: 10.1016/j.pneurobio.2012.02.003

Shah, V. B., Huang, Y., Keshwara, R., Ozment-Skelton, T., Williams, D. L., and Keshvara, L. (2008). $\beta$-glucan activates microglia without inducing cytokine production in Dectin-1-dependent manner. J. Immunol. 180, 2777-2785. doi: 10.4049/jimmunol.180.5.2777

Shao, A., Wu, H., Hong, Y., Tu, S., Sun, X., Wu, Q., et al. (2016). Hydrogenrich saline atenuated subarachnoid hemorrhage-induced early brain injury in rats by suppressing inflammatory response: possible involvement of NFкB pathway and NLRP3 inflammasome. Mol. Neurobiol. 53, 3462-3476. doi: 10.1007/s12035-015-9242-y

Sharp, F. A., Ruane, D., Claass, B., Creagh, E., Harris, J., Malyala, P., et al. (2009). Uptake of particulate vaccine adjuvants by dendritic cells activates the NALP3 inflammasome. Proc. Natl. Acad. Sci. U S A 106, 870-875. doi: 10.1073/pnas.0804897106

Shi, F., Kouadir, M., and Yang, Y. (2015). NALP3 inflammasome activation in protein misfolding diseases. Life Sci. 135, 9-14. doi: 10.1016/j.lfs.2015. 05.011

Shi, C. S., Shenderov, K., Huang, N. N., Kabat, J., Abu-Asab, M., Fitzgerald, K. A., et al. (2012). Activation of autophagy by inflammatory signals limits IL-1 $\beta$ production by targeting ubiquitinated inflammasomes for destruction. Nat Immunol. 13, 255-263. doi: 10.1038/ni.2215

Shi, H., Wang, Y., Li, X., Zhan, X., Tang, M., Fina, M., et al. (2016). NLRP3 activation and mitosis are mutually exclusive events coordinated by NEK7, a new inflammasome component. Nat. Immunol. 17, 250-258. doi: 10.1038/ni.3333

Shi, F., Yang, L., Kouadir, M., Yang, Y., Wang, J., Zhou, X., et al. (2012). The NALP3 inflammasome is involved in neurotoxic prion peptideinduced microglial activation. J. Neuroinflammation 9:73. doi: 10.1186/1742-2 094-9-73

Shi, J., Zhao, Y., Wang, K., Shi, X., Wang, Y., Huang, H., et al. (2015). Cleavage of GSDMD by inflammatory caspases determines pyroptotic cell death. Nature 526, 660-665. doi: 10.1038/nature15514

Shi, J. Q., Zhang, C. C., Sun, X. L., Cheng, X. X., Wang, J. B., Zhang, Y. D., et al. (2013). Antimalarial drug artemisinin extenuates amyloidogenesis and neuroinflammation in APPswe/PS1dE9 transgenic mice via inhibition of nuclear factor-кB and NLRP3 inflammasome activation. CNS Neurosci. Ther. 19, 262-268. doi: 10.1016/j.jalz.2013.04.112

Shrivastava, S. K., Dalko, E., Delcroix-Genete, D., Herbert, F., Cazenave, P. A., and Pied, S. (2017). Uptake of parasite-derived vesicles by astrocytes and microglial phagocytosis of infected erythrocytes may drive neuroinflammation in cerebral malaria. Glia 65, 75-92. doi: 10.1002/glia.23075

Sifringer, M., Stefovska, V., Endesfelder, S., Stahel, P. F., Genz, K., Dzietko, M., et al. (2007). Activation of caspase-1 dependent interleukins in developmental brain trauma. Neurobiol. Dis. 25, 614-622. doi: 10.1016/j.nbd.2006. 11.003

Silver, J., and Miller, J. H. (2004). Regeneration beyond the glial scar. Nat. Rev. Neurosci. 5, 146-156. doi: 10.1038/nrn1326

Silverman, W. R., de Rivero Vaccari, J. P., Locovei, S., Qiu, F., Carlsson, S. K., Sceme, S. E., et al. (2009). The pannexin 1 channel activates the inflammasome in neurons and astrocytes. J. Biol. Chem. 284, 18143-18151. doi: 10.1074/jbc. m109.004804

Sofroniew, M. V. (2005). Reactive astrocytes in neural repair and protection. Neuroscientist 11, 400-407. doi: 10.1177/1073858405278321

Sofroniew, M. V. (2009). Molecular dissection of reactive astrogliosis and glial scar formation. Trends Neurosci. 32, 638-647. doi: 10.1016/j.tins.2009. 08.002

Sosunov, A. A., Wu, X., Tsankova, N. M., Guilfoyle, E., McKhann, G. M. II., and Goldman, J. E. (2014). Phenotypic heterogeneity and plasticity of isocortical and hippocampal astrocytes in the human brain. J. Neurosci. 34, 2285-2298. doi: 10.1523/JNEUROSCI.4037-13.2014

Srinivasula, S. M., Poyet, J. L., Razmara, M., Datta, P., Zhang, Z., and Alnemri, E. S. (2002). The PYRIN-CARD protein ASC is an activating adaptor for caspase-1. J. Biol. Chem. 277, 21119-21122. doi: 10.1074/jbc.c200179200

Subramanian, N., Natarajan, K., Clatworthy, M. R., Wang, Z., and Germain, R. N. (2013). The adaptor MAVS promotes NLRP3 mitochondrial localization and inflammasome activation. Cell 153, 348-361. doi: 10.1016/j.cell.2013. 02.054

Sutterwala, F. S., Mijares, L. A., Li, L., Ogura, Y., Kazmierczak, B. I., and Flavell, R. A. (2007). Immune recognition of Pseudomonas aeruginosa mediated by the IPAF/NLRC4 inflammasome. J. Exp. Med. 204, 3235-3245. doi: 10.1084/jem.20071239

Sutterwala, F. S., Ogura, Y., Szczepanik, M., Lara-Tejero, M., Lichtenberger, G. S., Grant, E. P., et al. (2006). Critical role for NALP3/CIAS1/Cryopyrin in innate and adaptive immunity through its regulation of caspase-1. Immunity 24, 317-327. doi: 10.1016/j.immuni.2006.02.004

Szretter, K. J., Samuel, M. A., Gilfillan, S., Fuchs, A., Colonna, M., and Diamond, M. S. (2009). The immune adaptor molecule SARM modulates tumor necrosis factor alpha production and microglia activation in the brainstem and restricts West Nile Virus pathogenesis. J. Virol. 83, 9329-9338. doi: 10.1128/JVI.00836-09 
Tahara, K., Kim, H. D., Jin, J. J., Maxwell, J. A., Li, L., and Fukuchi, K. (2006). Role of toll-like receptor signalling in A $\beta$ uptake and clearance. Brain 129, 3006-3019. doi: 10.1093/brain/awl249

Tang, S. C., Wang, Y. C., Li, Y. I., Lin, H. C., Manzanero, S., Hsieh, Y. H., et al. (2013). Functional role of soluble receptor for advanced glycation end products in stroke. Arterioscler. Thromb. Vasc. Biol. 33, 585-594. doi: 10.1161/ATVBAHA.112.300523

Tan, M. S., Tan, L., Jiang, T., Zhu, X. C., Wang, H. F., Jia, C. D., et al. (2014). Amyloid- $\beta$ induces NLRP1-dependent neuronal pyroptosis in models of Alzheimer's disease. Cell Death Dis. 5:e1382. doi: 10.1038/cddis. 2014.348

Tan, M. S., Yu, J. T., Jiang, T., Zhu, X. C., Wang, H. F., Zhang, W., et al. (2013). NLRP3 polymorphisms are associated with late-onset Alzheimer's disease in Han Chinese. J. Neuroimmunol. 265, 91-95. doi: 10.1016/j.jneuroim.2013.10. 002

Tate, M. D., Ong, J. D., Dowling, J. K., McAuley, J. L., Robertson, A. B., Latz, E., et al. (2016). Reassessing the role of the NLRP3 inflammasome during pathogenic influenza A virus infection via temporal inhibition. Sci. Rep. 6:27912. doi: 10.1038/srep27912

Thakkar, R., Wang, R., Sareddy, G., Wang, J., Thiruvaiyaru, D., Vadlamudi, R., et al. (2016). NLRP3 inflammasome activation in the brain after global cerebral ischemia and regulation by $17 \beta$-estradiol. Oxid. Med. Cell. Longev. 2016:8309031. doi: 10.1155/2016/8309031

Thomas, P. G., Dash, P., Aldridge, J. R. Jr., Ellebedy, A. H., Reynolds, C., Funk, A. J., et al. (2009). The intracellular sensor NLRP3 mediates key innate and healing responses to influenza A virus via the regulation of caspase-1. Immunity 30, 566-575. doi: 10.1016/j.immuni.2009.02.006

Thønnings, S., Knudsen, J. D., Schønheyder, H. C., Søgaard, M., Arpi, M., Gradel, K. O., et al. (2016). Antibiotic treatment and mortality in patients with Listeria monocytogenes meningitis or bacteraemia. Clin. Microbiol. Infect. 22, 725-730. doi: 10.1016/j.cmi.2016.06.006

Tixador, P., Herzog, L., Reine, F., Jaumain, E., Chapuis, J., Le Dur, A., et al. (2010). The physical relationship between infectivity and prion protein aggregates is strain-dependent. PLoS Pathog. 6:e1000859. doi: 10.1371/journal.ppat. 1000859

Toldo, S., Mezzaroma, E., McGeough, M. D., Peña, C. A., Marchetti, C., Sonnino, C., et al. (2015). Independent roles of the priming and the triggering of the NLRP3 inflammasome in the heart. Cardiovasc. Res. 105, 203-212. doi: $10.1093 / \mathrm{cvr} / \mathrm{cvu} 259$

Tribouillard-Tanvier, D., Striebel, J. F., Peterson, K. E., and Chesebro, B. (2009). Analysis of protein levels of 24 cytokines in scrapie agent-infected brain and glial cell cultures from mice differing in prion protein expression levels. J. Virol. 83, 11244-11253. doi: 10.1128/JVI.01413-09

Tsuda, T., Munthasser, S., Fraser, P. E., Percy, M. E., Rainero, I., Vaula, G., et al. (1994). Analysis of the functional effects of a mutation in SOD1 associated with familial amyotrophic lateral sclerosis. Neuron 13, 727-736. doi: 10.1016/08966273(94)90039-6

Walsh, J. G., Reinke, S. N., Mamik, M. K., McKenzie, B. A., Maingat, F., Branton, W. G., et al. (2014). Rapid inflammasome activation in microglia contributes to brain disease in HIV/AIDS. Retrovirology 11:35. doi: 10.1186/1742-4690-11-35

Wang, J., and Doré, S. (2007). Inflammation after intracerebral hemorrhage. J. Cereb. Blood Flow Metab. 27, 894-908. doi: 10.1038/sj.jcbfm.9600403

Wang, X., Li, R., Wang, X., Fu, Q., and Ma, S. (2015). Umbelliferone ameliorates cerebral ischemia-reperfusion injury via upregulating the PPAR gamma expression and suppressing TXNIP/NLRP3 inflammasome. Neurosci. Lett. 600, 182-187. doi: 10.1016/j.neulet.2015.06.016

Warren, S. E., Mao, D. P., Rodriguez, A. E., Miao, E. A., and Aderem, A. (2008). Multiple Nod-like receptors activate caspase 1 during Listeria monocytogenes infection. J. Immunol. 180, 7558-7564. doi: 10.4049/jimmunol.180. 11.7558

Werner, C., and Engelhard, K. (2007). Pathophysiology of traumatic brain injury. Br. J. Anaesth. 99, 4-9. doi: 10.1093/bja/aem131

White, C. S., Lawrence, C. B., Brough, D., and Rivers-Auty, J. (2017). Inflammmasomes as therapeutic targets for Alzheimer's disease. Brain Pathol. 27, 223-234. doi: 10.1111/bpa.12478

Willingham, S. B., Bergstralh, D. T., O’Connor, W., Morrison, A. C., Taxman, D. J., Duncan, J. A., et al. (2007). Microbial pathogen-induced necrotic cell death mediated by the inflammasome components CIAS1/cryopyrin/NLRP3 and ASC. Cell Host Microbe 2, 147-159. doi: 10.1016/j.chom.2007.07.009

Wilms, H., Sievers, J., Rickert, U., Rostami-Yazdi, M., Mrowietz, U., and Lucius, R. (2010). Dimethylfumarate inhibits microglial and astrocytic inflammation by suppressing the synthesis of nitric oxide, IL- $1 \beta$, TNF- $\alpha$ and IL- 6 in an in-vitro model of brain inflammation. J. Neuroinflammation 7:30. doi: 10.1186/17422094-7-30

Witiw, C. D., and Fehlings, M. G. (2015). Acute spinal cord injury. J. Spinal Disord. Tech. 28, 202-210. doi: 10.1097/BSD.0000000000000287

Witten, I. B., Steinberg, E. E., Lee, S. Y., Davidson, T. J., Zalocusky, K. A., Brodsky, M., et al. (2011). Recombinase-driver rat lines: tools, techniques and optogenetic application to dopamine-mediated reinforcement. Neuron 72, 721-733. doi: 10.1016/j.neuron.2011.10.028

Wu, J., Fernandes-Alnemri, T., and Alnemri, E. S. (2010). Involvement of the AIM2, NLRC4 and NLRP3 inflammasomes in caspase-1 activation by Listeria monocytogenes. J. Clin. Immunol. 30, 693-702. doi: 10.1007/s10875-0109425-2

Xiao, M., Li, L., Li, C., Liu, L., Yu, Y., and Ma, L. (2016). 3,4-methylenedioxy- $\beta$ nitrostyrene ameliorates experimental burn wound progression by inhibiting the NLRP3 inflammasome activation. Plast. Reconstr. Surg. 137, 566e-575e doi: 10.1097/01.prs.0000479972.06934.83

Xian, W., Wu, Y., Xiong, W., Li, L., Li, T., Pan, S., et al. (2016). The pro-resolving lipid mediator Maresin 1 protects against cerebral ischemia/reperfusion injury by attenuating the pro-inflammatory response. Biochem. Biophys. Res. Commun. 472, 175-181. doi: 10.1016/j.bbrc.2016.02.090

Xie, G., Tian, W., Wei, T., and Liu, F. (2015). The neuroprotective effects of $\beta$-hydroxybutyrate on $\mathrm{A} \beta$-injected rat hippocampus in vivo and in $\mathrm{A} \beta$-treated PC-12 cells in vitro. Free Radic. Res. 49, 139-150. doi: 10.3109/10715762. 2014.987274

Xiong, Y., Mahmood, A., and Chopp, M. (2013). Animal models of traumatic brain injury. Nat. Rev. Neurosci. 14, 128-142. doi: 10.1038/nrn3407

Yang, F., Wang, Z., Wei, X., Han, H., Meng, X., Zhang, Y., et al. (2014). NLRP3 deficiency ameliorates neurovascular damage in experimental ischemic stroke. J. Cereb. Blood Flow Metab. 34, 660-667. doi: 10.1038/jcbfm.2013.242

Yang, Z., Zhong, L., Xian, R., and Yuan, B. (2015). MicroRNA-223 regulates inflammation and brain injury via feedback to NLRP3 inflammasome after intracerebral hemorrhage. Mol. Immunol. 65, 267-276. doi: 10.1016/j.molimm. 2014.12.018

Yatsiv, I., Morganti-Kossmann, M. C., Perez, D., Dinarello, C. A., Novick, D., Rubinstein, M., et al. (2002). Elevated intracranial IL-18 in humans and mice after traumatic brain injury and evidence of neuroprotective effects of IL-18binding protein after experimental closed head injury. J. Cereb. Blood Flow Metab. 22, 971-978. doi: 10.1097/00004647-200208000-00008

Yin, Y., Yan, Y., Jiang, X., Mai, J., Chen, N. C., Wang, H., et al. (2009). Inflammasomes are differentially expressed in cardiovascular and other tissues. Int. J. Immunopathol. Pharmacol. 22, 311-322. doi: $10.1177 / 039463200902200208$

Youm, Y. H., Nguyen, K. Y., Grant, R. W., Goldberg, E. L., Bodogai, M., Kim, D., et al. (2015). The ketone metabolite $\beta$-hydroxybutyrate blocks NLRP3 inflammasome-mediated inflammatory disease. Nat. Med. 21, 263-269. doi: $10.1038 / \mathrm{nm} .3804$

Yuan, B., Shen, H., Lin, L., Su, T., Zhong, S., and Yang, Z. (2015). Recombinant adenovirus encoding NLRP3 RNAi attenuate inflammation and brain injury after intracerebral hemorrhage. J. Neuroinflammation 287, 71-75. doi: 10.1016/j.jneuroim.2015.08.002

Yu, M., Zhang, K., Qi, W., Huang, Z., Ye, J., Ma, Y., et al. (2014). Expression pattern of NLRP3 and its related cytokines in the lung and brain of avian influenza virus H9N2 infected BALB/c mice. Virol. J. 11:229. doi: 10.1186/s12985-0140229-5

Zendedel, A., Johann, S., Mehrabi, S., Joghataei, M., Hassanzadeh, G., Kipp, M., et al. (2016). Activation and regulation of NLRP3 inflammasome by intrathecal application of SDF-1a in a spinal cord injury model. Mol. Neurobiol. 53, 3063-3075. doi: 10.1007/s12035-015-9203-5

Zhang, Y., and Barres, B. A. (2010). Astrocyte heterogeneity: an underappreciated topic in neurobiology. Curr. Opin. Neurobiol. 20, 588-594. doi: 10.1016/j.conb. 2010.06.005

Zhang, Q., Bian, G., Chen, P., Liu, L., Yu, C., Liu, F., et al. (2016). Aldose reductase regulates microglia/macrophages polarization through the cAMP response 
element-binding protein after spinal cord injury in mice. Mol. Neurobiol. 53, 662-676. doi: 10.1007/s12035-014-9035-8

Zhao, W., Beers, D. R., Bell, S., Wang, J., Wen, S., Baloh, R. H., et al. (2015). TDP43 activates microglia through NF-KB and NLRP3 inflammasome. Exp. Neurol. 273, 24-35. doi: 10.1016/j.expneurol.2015.07.019

Zhou, R., Tardivel, A., Thorens, B., Choi, I., and Tschopp, J. (2010). Thioredoxininteracting protein links oxidative stress to inflammasome activation. Nat. Immunol. 11, 136-140. doi: 10.1038/ni.1831

Zhou, R., Yazdi, A. S., Menu, P., and Tschopp, J. (2011). A role for mitochondria in NLRP3 inflammasome activation. Nature 469, 221-225. doi: $10.1038 /$ nature 09663
Conflict of Interest Statement: The authors declare that the research was conducted in the absence of any commercial or financial relationships that could be construed as a potential conflict of interest.

Copyright $\odot 2017$ Song, Pei, Yao, Wu and Shang. This is an open-access article distributed under the terms of the Creative Commons Attribution License (CC BY). The use, distribution and reproduction in other forums is permitted, provided the original author(s) or licensor are credited and that the original publication in this journal is cited, in accordance with accepted academic practice. No use, distribution or reproduction is permitted which does not comply with these terms. 